\title{
A Modeling Diagnosis of the Development of Mesoscale Convective Systems over the South China Sea during the Summer Monsoon Onset in 1998
}

\author{
Song-Chin Lin ${ }^{1, *}$ and Mien-Tze Kueh ${ }^{2}$
}

(Manuscript received 6 March 2003, in final form 13 August 2003)

\begin{abstract}
In this study, PSU/NCAR MM5 is used to simulate the evolution of the 1998 East Asian summer monsoon onset over the South China Sea (SCS). Simulation outputs are further utilized to study the development of mesoscale convective systems (MCSs) and their interactions with the synoptic/ large-scale environment in the SCS region. During the monsoon onset, over southern China and the SCS, high equivalent potential temperature, convective instability, and the southwesterly confluence in the lower troposphere provided favorable large-scale thermodynamic and dynamic conditions for the MCS development.

Model simulated results reveal that, in a warm-moist and unstable atmosphere, the downdraft outflows as a result of the MCS development could become a possible mesoscale triggering mechanism for the formation of a new MCS. Sensitivity tests depict the effect of latent heat release playing a significant role in the establishment of monsoon circulation. The terrain effect is significant for local cloud formation over land. For well organized MCSs occurring over the SCS, the influence of the mesoscale wind field is more important. The latent heat release in MCSs heats the atmosphere, reduces the surface pressure, and therefore enhances the lowlevel wind convergence and cyclonic circulation. The mesoscale adjustment of wind field and mass field, on one hand, enhances the MCS development or initiates the formation of a new MCS, and the organization of MCSs, on the other hand, integrates the mesoscale disturbances into a synoptic structure and forms the local monsoon trough. Without the latent heat release, monsoon circulation cannot establish itself even if the model provides favorable large-scale boundary forcing.
\end{abstract}

\footnotetext{
${ }^{1}$ Department of Atmospheric Sciences, National Central University, Chung-Li, Taiwan

${ }^{2}$ Central Weather Bureau, Taiwan

* Corresponding author address: Prof. Song-Chin Lin, Department of Atmospheric Sciences, National Central University, Chung-Li, Taiwan; E-mail: sclin@cc.ncu.edu.tw
} 


\section{(Key words: Summer monsoon onset, South China Sea, Mesoscale convective systems, Model diagnosis)}

\section{INTRODUCTION}

The East Asian summer monsoon is characterized by atmospheric circulations of different spatial and temporal scales. The major components of the monsoon system comprise the western Pacific subtropical high, the northeasterly flow associated with the upper-level anticyclone, the monsoon trough over the South China Sea (SCS) and western Pacific, the low-level southwesterly flow and the Mei-Yu front. The interaction between components of different scales leads to the maintenance and change of the monsoon circulation structure during its northward migration. The SCS, with its unique geographic location and being the convergent zone of tropical southeasterly, southwesterly and cross equatorial flows, has been thought to be the origin of the East Asian summer monsoon onset (Tao and Chen 1987; Lau and Yang 1997).

The SCS monsoon onset is a multi-scale adjustment process of atmospheric circulations, which is regarded as the outset of the northward intrusion of tropical warm-moist air. It is also a significant feature of seasonal transition in the East Asia. In the Asian monsoon region, SCS is the only region in the tropics where midlatitude frontal systems can reach. Chang and Chen (1995) pointed out that, with a favorable large-scale setting, the southwesterly flow associated with the front might bring in the warm-moist air from the tropics and trigger the outburst of convection over the SCS. Lin (1996) revealed that the southwesterly flow from the Bay of Bengal provided the thermodynamic mechanism for the westward and northward development of the South Asian anticyclone. The summer monsoon onset possibly could be triggered by the coincidence of the southwesterly moisture surge and the southward intrusion of the Mei-Yu front. Based on the analyses of low-level atmospheric circulations in the East Asian monsoon region, Kueh and Lin (2001) found that among 14 years during 1979 1995 the East Asian summer monsoon onset is accompanied by the frontal activities in the southern China area. Whether the southward intrusion of midlatitude fronts and the enhancement of southwesterly flows are significant signals of the SCS monsoon onset is still controversial. However, the role of frontal convective disturbances produced in the northern SCS region as a mesoscale triggering mechanism of the convections over the central and southern SCS is worth further investigation.

Ding and Liu (2001) pointed out that the SCS summer monsoon onset in 1998 consisted of two stages. In the first stage, sudden intensification of the southwesterly flow over the northern SCS and southward intrusion of the frontal cold air played important roles in triggering the monsoon onset. Johnson and Ciesielski (2002) also conducted a detailed study on the evolution of the first stage monsoon onset in the northern SCS region. However, further dynamic connection between the two stages of monsoon onset has not yet been studied. Though $\mathrm{Li}$ and $\mathrm{Wu}$ (2000) did not regard the first enhancement of the southwesterly flow over the northern SCS as the onset of summer monsoon, they also did not deny the important roles of 
the frontal southwesterly flow and convective activity in the monsoon onset processes. In their study, Shao and Qian (2000) depicted the SCS monsoon onset in 1998 as a process in which the southwesterly flow started first over the northern SCS, withdrew southward, and then propagated from south to north again.

Due to geographic differences, the northern SCS and the central-southern SCS exhibit different weather and climate regimes during the summer monsoon. Influences by alternate tropical southwesterly and midlatitude weather systems are found in the northern SCS region, while the tropical southwesterly is a major factor in the central-southern SCS region. However, convective activities over the central-southern SCS can still have connections with the frontal convective disturbances over the northern SCS. In this study, a numerical simulation of the 1998 summer monsoon onset is conducted by using PSU/NCAR MM5 (Pennsylvania State University/National Center for Atmospheric Research Mesoscale Model Version 5). Simulation results were further utilized to study the development and their interactions with the synoptic/large-scale environment of the mesoscale convective systems (MCSs) occurring in the SCS area. Sensitivity tests were also performed to investigate the influences of the tropical southwesterly and the surrounding terrain on local convections over the SCS.

\section{SYNOPTIC WEATHER AND CONVECTIVE ACTIVITY DURING THE SOUTH CHINA SEA SUMMER MONSOON ONSET IN 1998}

Based on the criteria of intensification of $850 \mathrm{hPa}$ westerly zonal wind and sudden increase of precipitation, Ding and Liu (2001) found that a burst of southwesterly occurred first in the fourth pentad of May over the northern SCS and then over the entire SCS in the fifth pentad. Retreat of the western Pacific subtropical high was also observed in both onset stages. They emphasized that the first onset stage was closely related to the rapid development of a cyclone over the Bay of Bengal and the southward propagation of the midlatitude front. $\mathrm{Li}$ and $\mathrm{Wu}$ (2000) defined the $21^{\text {st }}$ of May as the 1998 summer monsoon onset date when the southwesterly prevailed over the entire SCS and the subtropical high withdrew completely from the SCS. Determined by the intensifying signals of low-level southwesterly and upper-level easterly, Shao and Qian (2000) regarded the $25^{\text {th }}$ of May as the onset date. Chan et al. (2000) also treated the $25^{\text {th }}$ of May as the onset date, which is defined by the reversal of $850 \mathrm{hPa}$ zonal wind and a sudden increase of rainfall over the SCS with 5-day running mean data. Instead of a specific onset date, this study regards 18 25 May as the 1998 summer monsoon onset period based on the discussions in Kueh and Lin (2001). Major factors considered in Kueh and Lin (2001) are the $850 \mathrm{hPa}$ flow pattern, the eastward retreat of the subtropical high and convective activities over the SCS. The onset period determined in this way also covers the specific onset dates defined by the aforementioned studies. In order to investigate the convective activities occurring over the SCS in detail, this study further divides the whole evolution of the onset process into three sub-periods based on the cloud features revealed by the enhanced GMS5 satellite images.

The first sub-period, spanning 15 May to 19 May, represents the days of pre-onset and early onset. During this sub-period, cold air intruded southeastward persistently from the Asian 
continent with cold front extending westward to the coast of southern China and the northern SCS. Convective clouds developed continually in the warm sector of frontal zone along $20^{\circ} \mathrm{N}$ latitude, while it was still clear in the central-southern SCS south of $15^{\circ} \mathrm{N}$ latitude. The second sub-period (20 22 May) represents a short span of transition from local convective activities in the northern SCS to a full development of convection in the central-southern SCS. The convective clouds ceased gradually in the northern SCS and began to develop in the centralsouthern SCS. In the meantime, a new cloud cluster associated with a surface low pressure center began to grow and move southward. From 23 May to 25 May is the third sub-period that denotes the full onset over the entire SCS. Comparably larger MCSs were observed in the central-southern SCS with fragmentary clouds evolving in the northern SCS. Until the $25^{\text {th }}$ of May, the SCS was covered with convective clouds. Strong convections were found in a zone along $10^{\circ} N$ latitude.

In the following, synoptic weather conditions and convective activities for the three subperiods will be further illustrated.

\subsection{Synoptic Weather Analyses}

Figure 1 shows JMA (Japan Meteorological Agency) 0000UTC surface weather maps of selected dates during the summer monsoon onset. The first cold front which occurred in the first sub-period arrived at the coast of southern China at 0000UTC on 15 May (Fig. 1a). This front with a weakening cold core high pressure center $\mathbf{H}_{1}$ behind it moved eastward to the ocean on 16 May (not shown). Another high pressure center $\mathbf{H}_{2}$ moved southward immediately from north to around $30^{\circ} \mathrm{N}$ and then moved northeastward again. At 0000UTC on 18 May, the associated cold front had moved to the ocean east of Taiwan and became stationary with frontal surface passing through Taiwan to the coast of southern China (Fig. 1b). This is the second cold front appearing in the first sub-period. Over the SCS, no significant weather change was observed during this sub-period.

The major feature of the second sub-period is the development of a surface low pressure system (denoted by $\mathbf{L}$ on the maps). At 0000UTC on 20 May, in the northern high-latitude area, a low pressure center was formed in the warm sector to the south of an eastward moving cold front (Fig. 1c). This low pressure system, accompanied with cloud clusters at its southeastern flank, moved southeastward progressively and reached the Szuchuan Basin at 0000UTC on 21 May (Fig. 1d). Meanwhile, high pressure $\mathbf{H}_{2}$ moved to the ocean northeast of Korea and finally weakened at 1800UTC 21 May (not shown). During the evolutions of $\mathbf{L}$ and $\mathbf{H}_{2}$, the southerly wind component increased appreciably in the central and southern China areas due to the increase of an east-west pressure gradient. In a subsequent time, at 0000UTC on 22 May, while $\mathbf{L}$ moved southward out of the Szuchuan Basin, another high pressure system formed north of $40^{\circ} \mathrm{N}$ and moved rapidly eastward. To the northeast of $\mathbf{L}$, a new front formed (Fig. 1e). The synoptic setting over the northern SCS had apparent changes during this subperiod. An east-west oriented low pressure zone was found along $20^{\circ} \mathrm{N}$ in the northern SCS region and the coastal area of southern China. The relatively weak low pressure center embedded in the low pressure zone near the Bashi Channel (Fig. 1d) moved eastward and then northeastward following the frontal path (Fig. le). These small and weak low pressure centers 


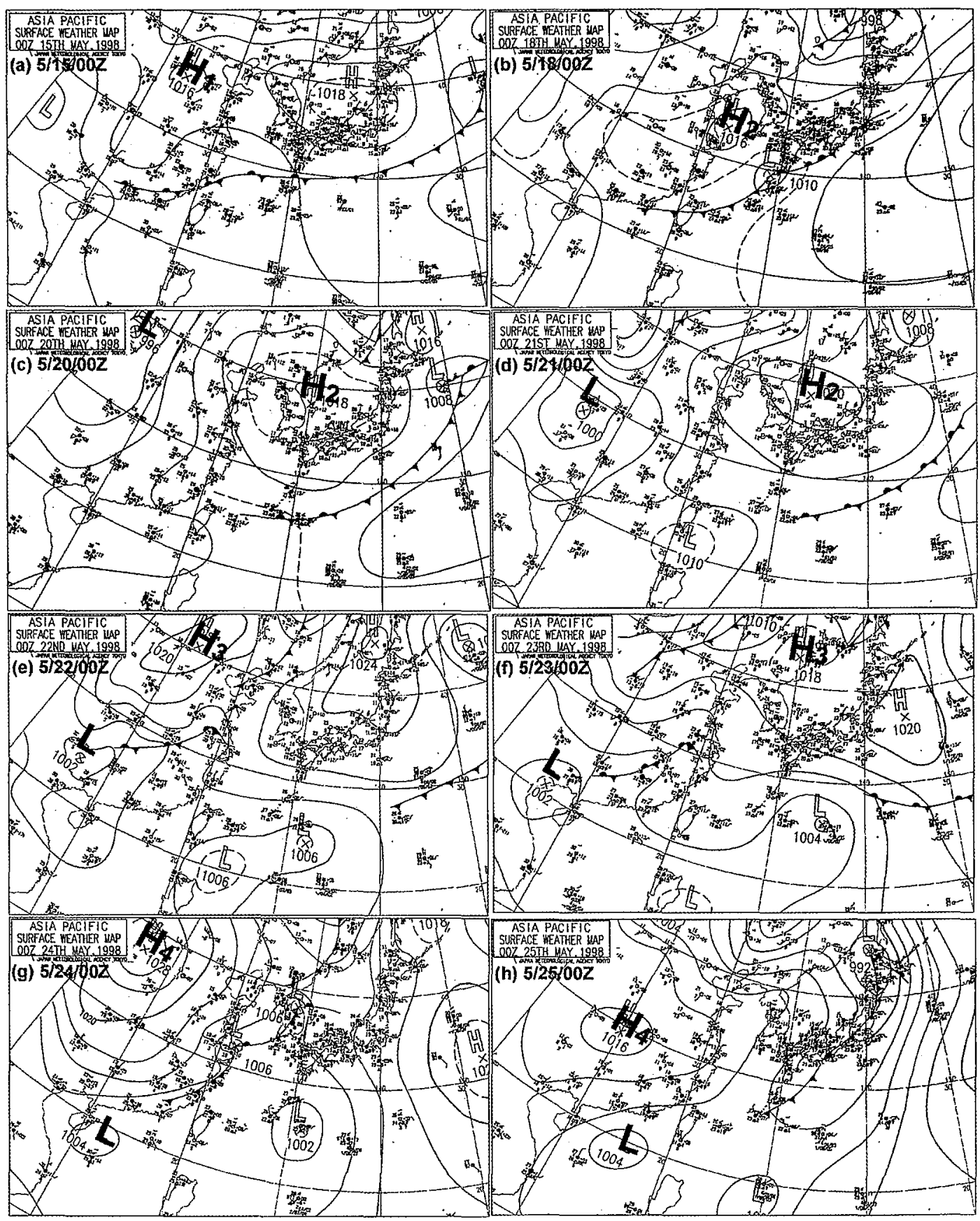

Fig. 1. JMA 0000UTC surface weather maps of selected dates during 15 25 May. Date is indicated in the upper-left corner of each panel. 
could possibly be the residuals of the dissipating frontal clouds.

Spanning the third sub-period, from 23 May to 25 May, the synoptic setting changed remarkably over the East Asian continent and the SCS. On 23 May, while high pressure $\mathbf{H}_{3}$ moved eastward to the ocean, surface low pressure center $\mathbf{L}$ and the front to its northeast moved southward (Fig. lf). Following this, a strong cold-core high pressure center $\mathbf{H}_{4}$ propagated rapidly southward from $45^{\circ} \mathrm{N}$ to $30^{\circ} \mathrm{N}$, and then weakened (Fig. $1 \mathrm{~h}$ ). During the southward intrusion of strong cold air, the front moved eastward to the ocean and the low pressure center $\mathbf{L}$ moved southeastward into the Bay of Tongkin. The low pressure center $\mathbf{L}$ then, passing the Hainan island, moved eastward continually.

\subsection{Mesoscale Convective Activities}

Serial convective clouds developed and then decayed gradually over the ocean east of Hainan island after the arrival of the first front on 15 May. These convective systems reached their maximum intensity in the afternoon with distinct diurnal variations. In the subsequent 12 hours after 0000UTC on 16 May, several fragmentary clouds organized into a couple of MCSs of relatively larger size. They are indicated by $\mathbf{A}, \mathbf{B}, \mathbf{C}_{1}$ and $\mathbf{C}_{2}$ in Fig. 2a. Six hours later at 1800UTC, $\mathbf{C}_{1}$ and $\mathbf{C}_{2}$ moved eastward and merged into a larger MCS $\mathbf{C}$ covering the whole area of the Bay of Tongkin (Fig. 2b). The MCS B grew and moved southward a little bit, while MCS A became stationary but exhibited features of persistent rebirth and dissipation (denoted by $\mathbf{A}^{\prime}$ in Fig. 2b). At 0000UTC on 17 May, A', B and $\mathbf{C}$ merged again into an even larger MCS D (Fig. 2c). The evolution of convective systems over the ocean showed a feature that the larger MCS endured in longer life and reached their maximum intensity in the early evening. The convective clouds oyer Indo-China, however, maintained a distinct diurnal variation and reached their maximum intensity in the afternoon. The MCS $\mathbf{D}$ then moved southward down to $15^{\circ} \mathrm{N}$ and evolved, with the frontal clouds, into a northeast-southwest oriented convective cloud band. In the evening of 17 May, MCS D began to dissipate and a new MCS D' appeared in the northeast near the western end of the front (Fig. 2d).

Fujita (1959) pointed out that, during the decaying stage of an intense convective system, the evaporative effect of raindrops within the descending flow could lead to the development of a meso-high pressure. As seen in the satellite cloud images, the boundary of a meso-high pressure often is revealed as an arc-shaped cloud band evolving out from the decaying convective system (Purdom 1973). Purdom (1979) further emphasized that the arc-shaped cloud band played a critical role in the formation and development of a new intense convective system. Numerical simulation results of Zhang and Bao (1966a, b) and their related earlier studies (Zhang and Fritsch 1986, 1987) also demonstrated the important role of outflow boundaries in the initiation of a new MCS. In the present study, the triggering of new convections in the vicinity of a decaying convective system could occur in a chain and is very likely the mechanism accounting for the evolution of convective systems over the SCS.

During 18-19 May, at the western end of the frontal zone, the development of MCSs exhibited the formation, eastward moving, merging and decaying processes. Two types of convective cloud patterns, roughly in line-shape perpendicular to the frontal surface, were observed near the western end of the frontal zone. One type of clouds formed over land and 

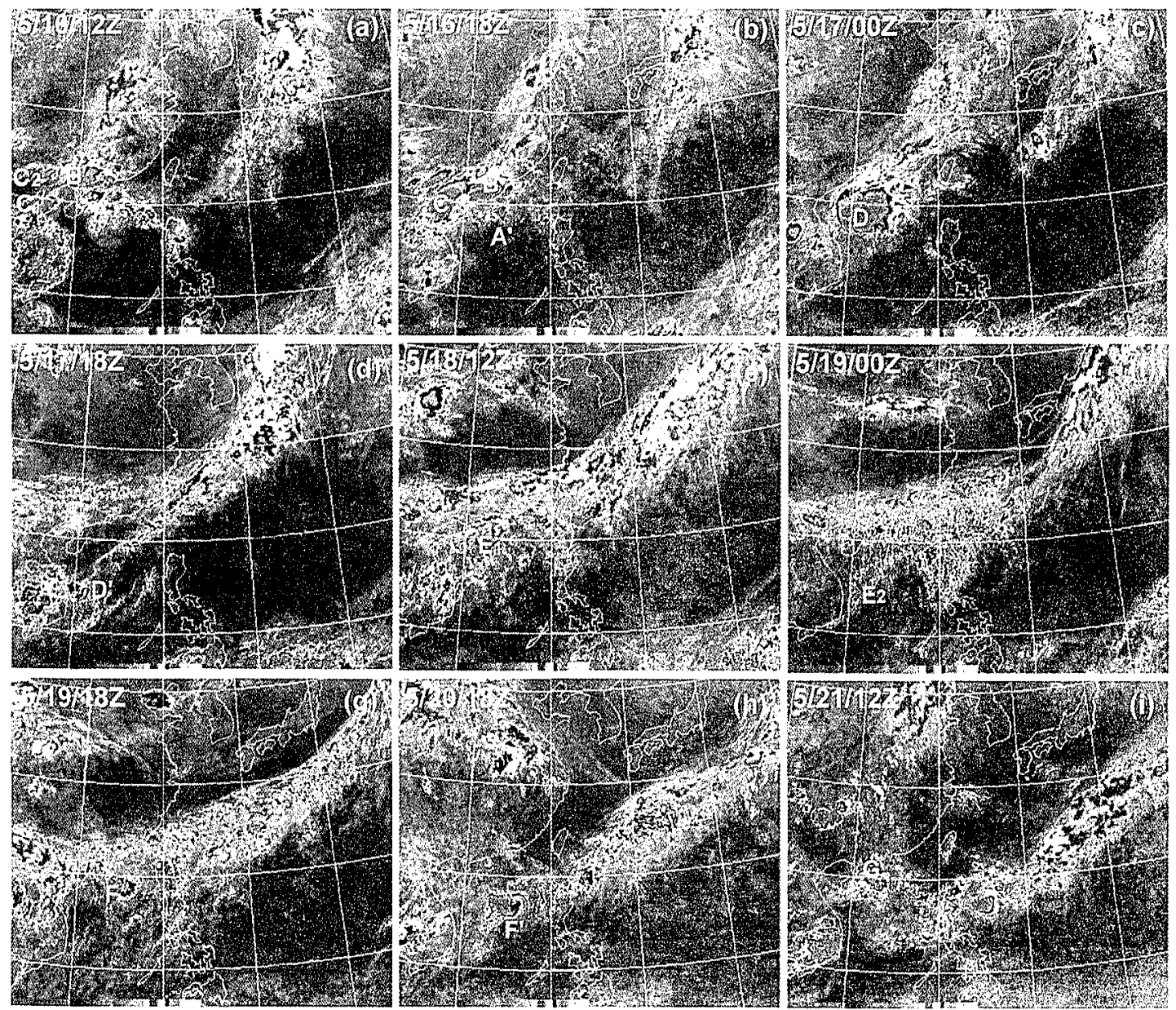

Fig. 2. GMS enhanced satellite IR images of selected times during 16 25 May.

Date and time are indicated in the upper-left corner of each panel.

then grew up over ocean, such as MCS $\mathbf{E}_{1}$ in Fig. 2e. The other type of clouds began to decay once moving over ocean, but new cells developed, such as MCS $\mathbf{E}_{\mathbf{2}}$ in Fig. 2f. On 18 May the line convection was oriented in the northwest-southeast direction (Fig. 2e), but changed into northeast-southwest direction on 19 May (Fig. 2f). The $850 \mathrm{hPa}$ prevailing wind over the northern SCS also changed from southeasterly to southwesterly during the orientation shift of line convections, indicating a close relationship between the low-level wind field and the development of convection. At 1800UTC on 19 May one of the arc-shaped cloud bands evolved and organized into a new MCS F with several intense convective cells inside (Fig. 2g). After formation, MCS F stayed temporarily over the northern SCS and then reorganized into another new MCS F' (Fig. 2h) after cell separation and dissipation.

The MCS F' moved southward first, then mixed and ceased gradually with the frontal 

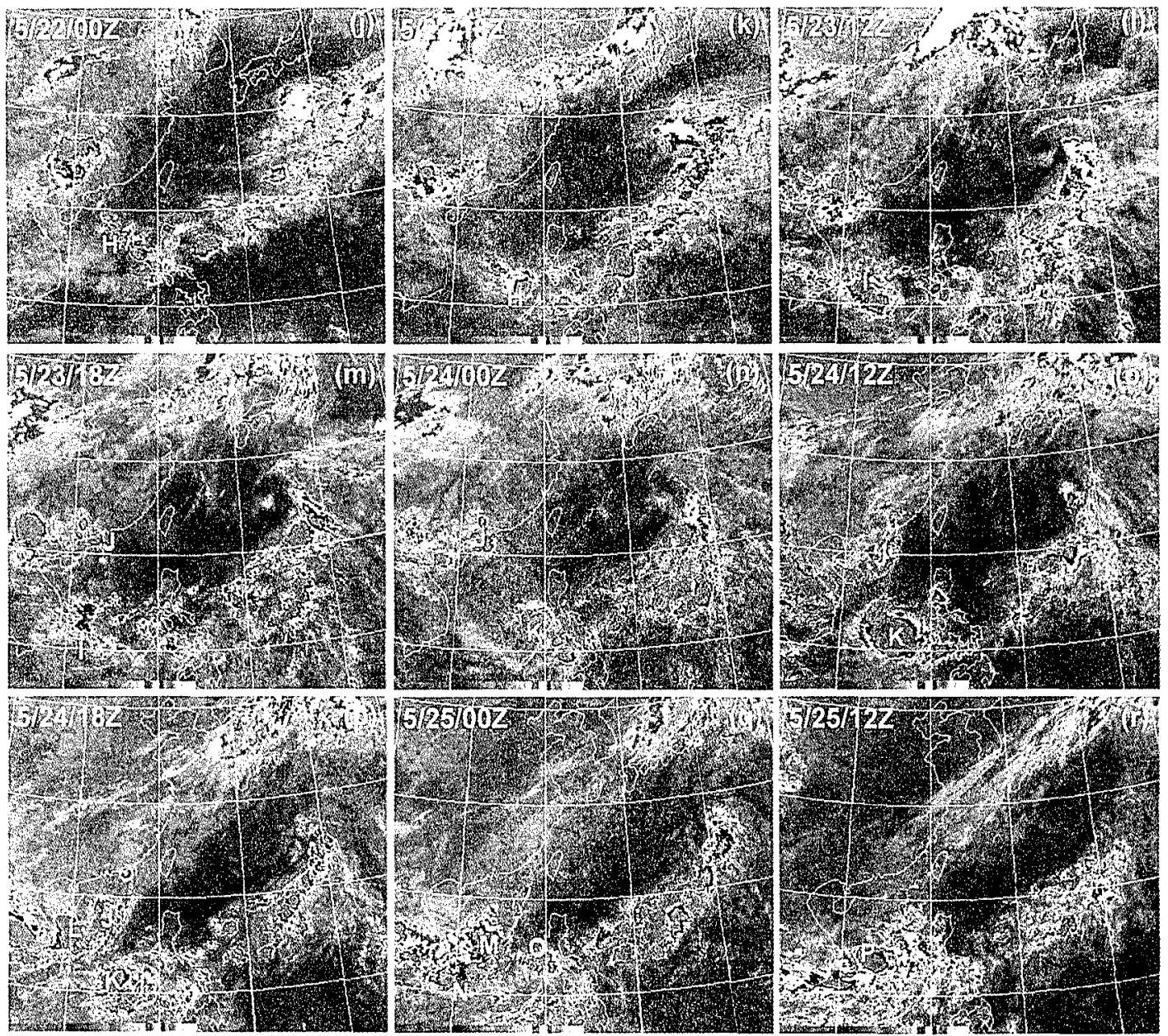

Fig. 2. Continued.

clouds. While MCS $\mathbf{F}^{9}$ was decaying, a new MCS $\mathbf{G}$ formed to the east of Hainan island. At 1200UTC on 21 May, MCS $\mathbf{G}$ and the remnants of $\mathbf{F}^{\prime}$ aligned into a line convection oriented in the northwest-southeast direction (Fig. 2i). Twelve hours later at 0000UTC on 22 May (Fig. $2 \mathrm{j}$ ), another new cell $\mathbf{H}$ started to develop at the northern tip of the line convection. In the evening on the same day, this new cell further moved southeastward, leaving the northern SCS a clear sky temporarily (Fig. 2k). The MCS $\mathbf{H}$ didn't last too long. When $\mathbf{H}$ was decaying, an arc cloud to its west developed into a new intense MCS I (Fig. 21). In contrast to the MCSs which occurred before, MCS I moved in a west-southwest direction and ceased gradually (Fig. 2m).

During the period from 1800UTC 23 May to 0000UTC 24 May, the remnants of MCS I merged with small convective clouds near the Philippines into a new MCS K (Fig. 2n). The MCS K shifted a little bit southward but grew rapidly into a MCS of considerable size (Fig. 
2o). Accompanied with the growth of MCS K, several MCSs also developed over the northern SCS near Hainan island (indicated by $\mathbf{J}$ and $\mathbf{L}$ in Fig. 2p). Up to this moment, regarded as the onset of summer monsoon by many previous studies, the entire SCS were nearly covered with deep convections. After the onset, dissipation and redevelopment of MCSs sustained for several cycles until early June (see one of the examples in Figs. 2q, r).

\subsection{Surface Observations at Dongsha and Nansha Islands}

Surface observations taken at Dongsha $\left(20^{\circ} 42^{\prime} \mathrm{N}, 116^{\circ} 43^{\prime} \mathrm{E}\right)$ and Nansha $\left(10^{\circ} 23^{\prime} \mathrm{N}\right.$, $114^{\circ} 22^{\prime} \mathrm{E}$ ) islands during the 1998 SCSMEX (South China Sea Monsoon Experiment) were further shown to illustrate the transitional characteristics of monsoon onset in the northern SCS and the central-southern SCS regions. Figures $3 \mathrm{a}$, b show the time series of surface observations at the Dongsha island. Before 15 May, the sky was almost clear, except for short durations of very weak precipitation occurring on 2 and 4 May (Fig. 3a). On 15 May and during 18-20 May, intense precipitations occurred, which were related to two frontal passages in the first sub-period. Between 20 May and 30 May, perceivable precipitation was measured only on 24 May. Observed relative humidity shown in Fig. 3a behaves consistently with the measured precipitation. After full monsoon onset, the relative humidity maintained a high value, above $85 \%$. The observed surface winds in Fig. $3 \mathrm{~b}$ show variable wind directions before the onset, and in prevailing southwesterlies after the onset.

The time series of surface observations at the Nansha island show distinct seasonal varia-
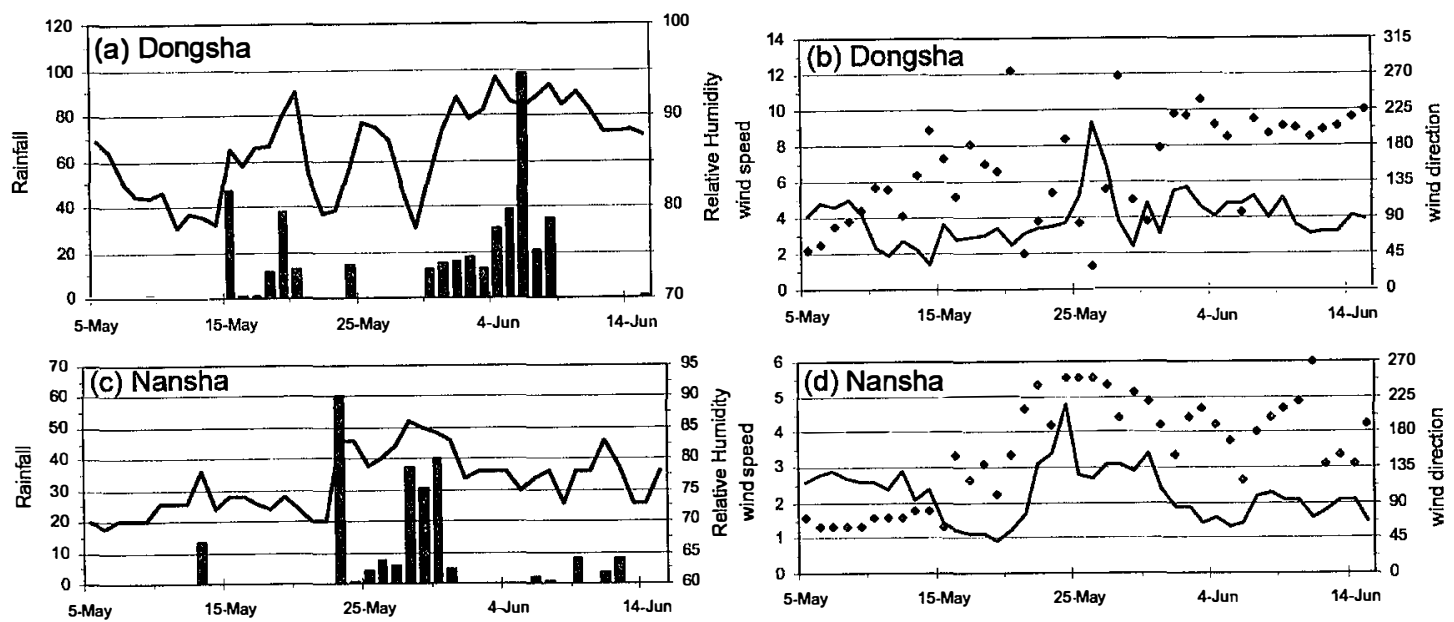

Fig. 3. Daily surface observations of the Dongsha (a, b) and the Nansha (c, d) islands for time period 5 May 15 June. In the left panels are 24-hour accumulated rainfall (vertical bar with units in $\mathrm{mm}$ ) and daily averaged relative humidity (thick line with units in \%), while in the right panels are daily averaged wind direction (black dot) and wind speed (grey line with units in $m s^{-1}$ ). 
tions and depict clearly the monsoon onset process. Sudden increase of intense precipitation was observed coincidently with the monsoon onset (Fig. 3c). The very intense rainfall measured on 23 May was produced by the MCS I in Fig. 21. The relative humidity was also raised and maintained at a high value after the onset (Fig. 3c). Transitional variations of wind direction and wind speed (Fig. 3d) are more evident than those revealed by the observations at the Dongsha island. In early May, Nansha island was located to the south of the subtropical high ridge. The surface wind was mainly from an east-northeast direction. In the middle of May when the subtropical high weakened, the surface wind became southeasterly with wind speed somewhat reduced. However, the wind speed increased remarkably and the wind direction switched from southeasterly to southwesterly near the stage of full monsoon onset. The change of wind direction and the sudden increase of the westerly wind component could be partly due to the eastward retreat of the subtropical high and the moving of low pressure center $\mathbf{L}$ into the SCS area. As revealed by Zhang and Bao (1966a, b) in a case study of a long-lived midlatitude MCS development, the convective activities could also play an important role in the maintenance of the low pressure center and the enhancement of the southwesterly wind. This will be further discussed in Section 4.

\section{MM5 MODEL DESCRIPTION AND SIMULATION DESIGN}

The spatial and temporal resolution of conventional sounding data is not sufficient to discern the mesoscale circulation characteristics of convective systems occurring over southern China and the SCS during the summer monsoon. Sounding observation alone is also incapable of examining the forcing and feedback mechanisms between the mesoscale circulation and its environment. Model simulation is therefore the most effective tool. PSU/NCAR MM5 has been used successfully in simulating MCS development and low-level jet formation associated with a Mei-Yu front (Chen et al. 1997, 1998a, b). This study thus conducted a model simulation of the 1998 summer monsoon onset by using MM5. Simulation results were further utilized to investigate the development and their interaction with the synoptic/large-scale environment of the MCSs occurring in southern China and the SCS regions.

The MM5 is a 3-dimensional non-hydrostatic, primitive equation model with terrain following vertical coordinates. The model is capable of multiple nesting to account for scale interactions, and has rather complete physics. The physical parameterizations include precipitation, planetary boundary layer, radiation, and surface fluxes (Grell et al. 1995). The initial inputs adopt NCEP GDAS (National Center for Environmental Predictions Global Data Assimilation System) $2.5^{\circ} \times 2.5^{\circ}$ latitude/longitude grid data with a 12-hour interval. Model simulations were performed on two nested interactive grids as shown in Fig. 4. The coarse grid (D01) is a $90 \mathrm{~km}$ grid with a mesh size of $52 \times 42$, and the fine grid (D02) is a $30 \mathrm{~km}$ grid with a mesh size of $64 \times 64$. Both grids have $23 \sigma$-levels in the vertical. The coarse grid domain covers the East Asian continental region, the Indo-China peninsula, the SCS and the western Pacific. The fine grid domain covers only the SCS region, which is intended for studying the triggering mechanism of the MCS development.

In order to examine the role of convective latent heating and the effect of surrounding 


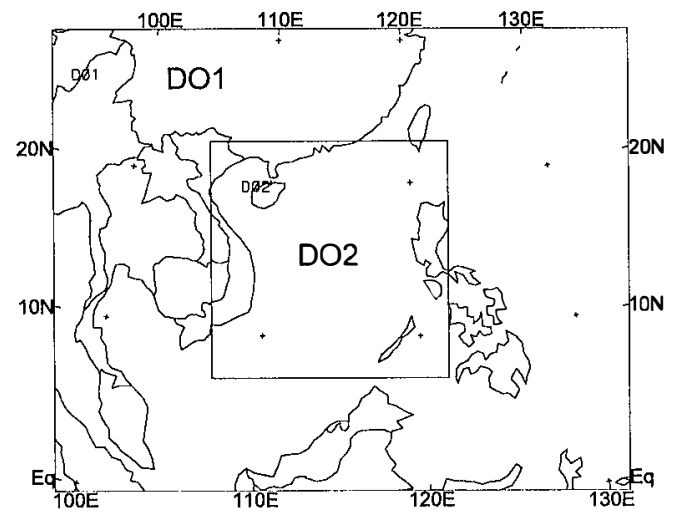

Fig. 4. Coarse (DO1) and fine (DO2) model domains for this study.

terrain in the MCS development over the SCS, three model runs were designed, including a control case (CNTL), a case without latent heat release (NLHR), and a case using low resolution terrain data (LTER). For the control case, the coarse grid and the fine grid use 30 minute $(\sim 56 \mathrm{~km})$ and 10 minute $(\sim 19 \mathrm{~km})$ terrain data, respectively. The simple ice scheme is specified to account for the resolvable precipitation, while the Grell cumulus parameterization scheme is chosen to treat the subgrid-scale convective clouds (Grell et al. 1995). A high-resolution Blackadar's planetary boundary layer parameterization scheme is used to forecast the surface vertical eddy fluxes (Zhang and Anthes 1982). The NLHR case has essentially the same specifications as those of the CNTL case, except that grid- and subgrid-scale latent heat releases of condensation are ignored. The design of the NLHR case is to test whether the MCS development over the SCS has significant influences on the enhancement of the southwesterly wind or not. Both grid domains of the LTER case use one degree $(\sim 111 \mathrm{~km})$ low-resolution terrain data with the same initial inputs and physical parameterizations as specified by the CNTL case. The LTER case is performed by reducing the terrain slopes to understand the barrier effect of the western terrain boundary on the eastward marching of the southwesterly flow.

\section{SIMULATION RESULTS AND DIAGNOSES}

To validate the model simulations, we first compare the $850 \mathrm{hPa}$ height and wind fields produced by the CNTL runs with the observed fields. Figure 5 shows the daily averaged 850 $\mathrm{hPa}$ observed height and wind analyses for the period 18-25 May. The observed features of the first sub-period include the eastward retreat of the subtropical high, the $850 \mathrm{hPa}$ height falling over the SCS, the gradual increase of the southwesterly over the northern SCS, and the development of a weak pressure trough near Hainan island (Figs. 5a, b). During the second subperiod (Figs. 5c, d, e), the low pressure system $\mathbf{L}$ and the pressure trough associated with the surface front moved eastward, the intense north-south pressure gradient built up and the west- 
erly wind component increased over the northern SCS, the $850 \mathrm{hPa}$ height fell and the wind weakened over the southern SCS. At the monsoon onset (Figs. 5f, g, h), southwesterly flow from the Tropics enhanced noticeably, intense north-south pressure gradient and strong southwesterly extended to the central-southern SCS, a cyclonic low pressure center developed over the northern SCS. The corresponding simulated $850 \mathrm{hPa}$ height and wind fields of the coarse domain are shown in Fig. 6. Comparisons show reasonable agreement between observed and simulated fields. The model simulations basically can capture the major features of each subperiod. In the following discussions, the simulated precipitation is a 12-hour accumulated value. When discussed in association with the accumulated precipitation, the sea level pressure and surface wind mentioned will be those of the last time period of the 12-hour interval, and the divergence field referred to will be the 12-hour time-averaged value. For the purpose of discussing MCS development, the locations of perceivable accumulated precipitation will be treated as the model simulated MCSs.

\subsection{The First Sub-period - Frontal Activities}

In the first sub-period, a frontal cloud band appeared stationary along the coast of southern China, several MCSs formed in the warm sector and gradually organized into a convective cloud band perpendicular to the front. Figure 7 shows the accumulated precipitation with 850
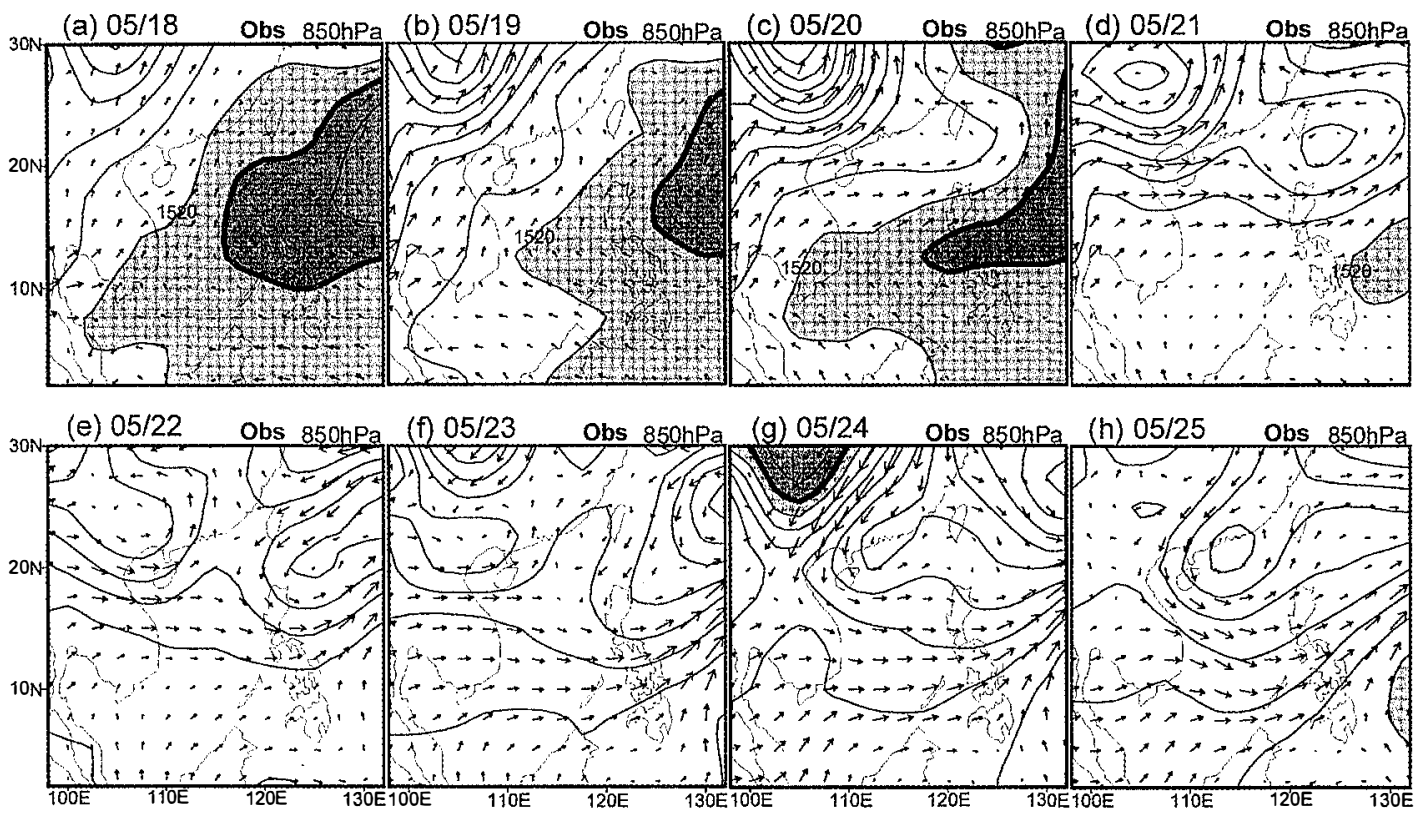

Fig. 5. Daily averaged $850 \mathrm{hPa}$ observed height (solid line) and wind (vector) analyses for time period 18-25 May. Date is indicated at the top of each panel. The contour interval of height field is $10 \mathrm{~m}$ with values above $1520 m$ shaded. 
$\mathrm{hPa}$ wind analysis (left panels) and the $925 \mathrm{hPa}$ divergence with $200 \mathrm{hPa}$ wind analysis (right panels) of the 12-hour periods, 1200UTC 17 May 0000UTC 18 May and 0000UTC 18 May 1200UTC 18 May, for the coarse domain CNTL runs. The accumulated precipitation analysis reveals an intense cloud band extending northeastward from the coast of southern China. To the south of the cloud band, there is an organized north-south oriented convective cloud band. The former is the frontal cloud band and the latter is a band-shaped organized MCSs developing in the warm sector of the front. Compared with Figs. 2d, e, the model seems to be able to simulate the major convective activity in the first sub-period. For the period 1200UTC 17 May 0000UTC 18 May, over the northern SCS, the $850 \mathrm{hPa}$ southwesterly flow near the southern end of the organized MCS mainly came from the outflow of the subtropical high (Fig. 7a). But, during the period 0000UTC 18 May 1200UTC 18 May, the frontal cloud band somewhat weakened and the MCS formation in the warm sector became active, the origin of southwesterly flow over the northwestern SCS gradually switched to the western side (Fig. 7c). Also shown in Figs. 7b, d, the $925 \mathrm{hPa}$ convergent zones match well with MCS (accumulated precipitation) locations, and an upper-level diffluent flow pattern can be seen over southern China and the northern SCS in the $200 \mathrm{hPa}$ wind analyses.

Figure 8 shows the accumulated precipitation with $1000 \mathrm{hPa}$ wind analysis (left panels) and sea level pressure (right panels) of the fine domain CNTL runs for the same time periods as shown in Fig. 7. Over the northern SCS, low-level wind divergence or convergence was found in local areas within and around the MCS. This kinematic feature plays an important role in the MCS development. At 0000UTC on 18 May, the MCS located to the southeast of Hainan island was accompanied with low-level convergence (Fig. 8a). Thus, it grew vigor-

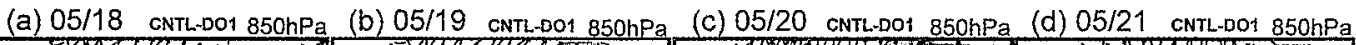

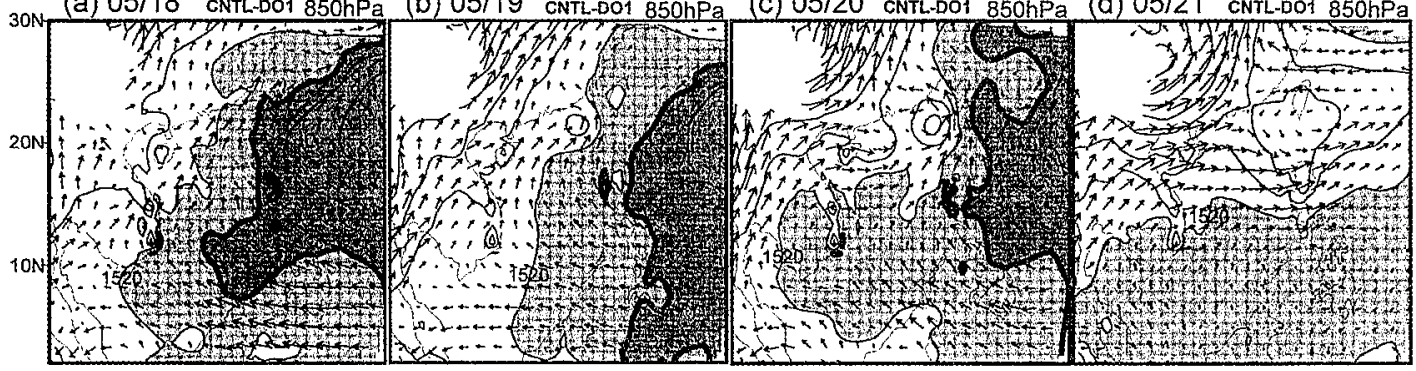

(e) $05 / 22$ cNTL-DO1 850hPa (f) 05/23 cNTL-DO1 $850 \mathrm{hPa}$ (g) 05/24 cNTL-DO1 850hPa (h) 05/25 CNTL-DO1 850hPa

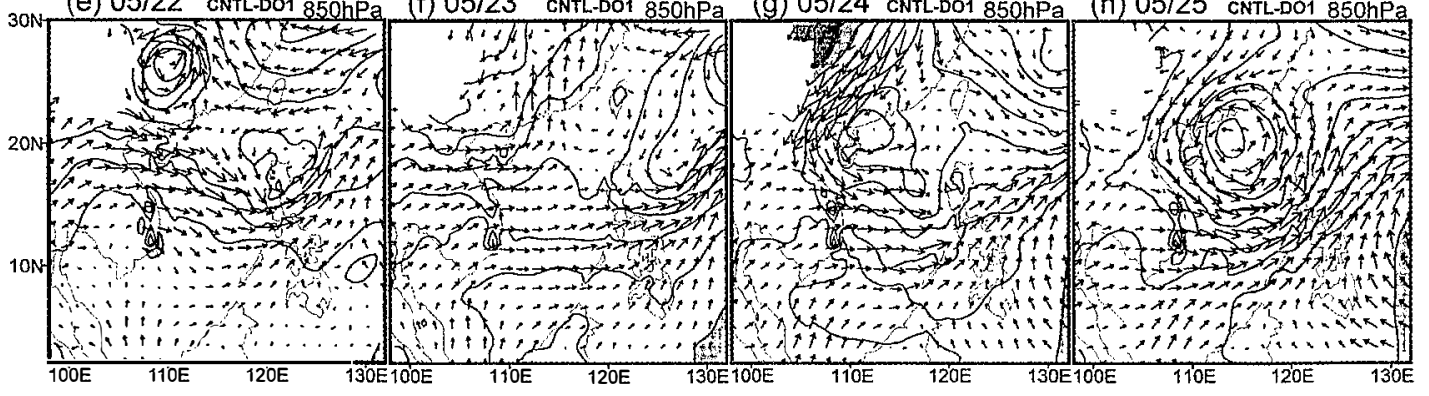

Fig. 6. Same as Fig. 5 except for coarse domain CNTL runs. 
ously in the following 12 hours (Fig. 8c). Another example is the line-shaped MCS located to the west of the Philippines. At 0000UTC on 18 May, low-level wind divergence and convergence were seen in the northern and the southern sections of the MCS, respectively (Fig. 8a). In the next 12 hours, the southern section of the MCS continued growing, but the northern section dissipated due to unfavorable conditions (Fig. 8c). As seen in 3-hour simulation outputs (not shown), the initiation of a new MCS of ten happens in a time scale shorter than 12 hours and most frequently in the western and the southern peripheries of a decaying MCS since the environmental flows are mainly from the southwest. Phenomena observed in model simulations suggest that the low-level outflow of a decaying MCS may play a triggering role in the formation of a nearby new MCS if the outflow and its environment constitute a favorable condition for convection. This result supports the observational analyses of Purdom (1979) and is consistent with the numerical simulations of Zhang and Bao (1996a, b). During 1200UTC 17 May 1200UTC 18 May over the northern SCS, though the large-scale environment had high equivalent potential temperature and was convectively unstable in the lower troposphere, the horizontal temperature gradient across the frontal zone was weak. Thus, mesoscale forcing plays the primary role in the development of MCS, but not the frontal lifting. In the sea level pressure analyses shown in Figs. 8b, d, mesoscale low pressure and high pressure are found in the developing and decaying stages of a MCS, respectively. Taking the MCS which located to the southeast of Hainan island as an example, the low-level wind convergence occurred in a local area of low pressure at its growing stage (Fig. 8b). This low pressure zone became a high pressure center as the MCS began to decay (Fig. 8d).

Coarse domain CNTL and NLHR model simulations of sea level pressure, $850 \mathrm{hPa}$ equivalent potential temperature, $850 \mathrm{hPa}$ wind and $200 \mathrm{hPa}$ wind analyses along $20^{\circ} \mathrm{N}$ and $15^{\circ} \mathrm{N}$ latitude lines are displayed in time sequence as shown in Fig. 9. The left panels of CNTL runs (Fig. 9a, b) show that high $850 \mathrm{hPa}$ equivalent potential temperature, low sea level pressure and increasing of $850 \mathrm{hPa}$ southerly or southwesterly wind were found during the MCS development. On the other hand, increasing of sea level pressure, decreasing of $850 \mathrm{hPa}$ equivalent potential temperature, weakening of $850 \mathrm{hPa}$ southwesterly wind or diffluent flow were found during the MCS decaying stage. The north-south differences in the upper-level $200 \mathrm{hPa}$ winds are more evident. Short durations of $200 \mathrm{hPa}$ wind direction variations were associated with the MCS development over the northern SCS $\left(20^{\circ} \mathrm{N}\right)$. To its south over the central SCS $\left(15^{\circ} \mathrm{N}\right)$, the upper-level winds are relatively weak, and there appear increasing northerly wind components during the MCS development. The NLHR simulations shown in Figs. 9c, d depict that, without latent heat release, the $850 \mathrm{hPa}$ southwesterly wind over the entire SCS became weaker apparently, and the $850 \mathrm{hPa}$ easterly wind component coming from the outflow of the subtropical high became stronger over the central SCS. The upper-level northwesterly wind strengthened persistently, particularly over the central SCS. Sea level pressures along both latitudes were also raised appreciably. These contrasts between CNTL and NLHR runs reveal the significant influence of the MCS development on the environmental flow.

Accumulated precipitations simulated by coarse and fine domain LTER runs show similar distributions to those of CNTL runs (not shown). The only difference is that few fragmentary clouds appear over Indo-China and the vicinity of Hainan island. This suggests that terrain effect is significant for local clouds. But, for well organized MCSs over the SCS, influ- 


\section{CNTL-DO1}

$051800850 \mathrm{hPo}$

(a) $>>$ wind(vector) \& isotoch(contour) 051712 051800 acc. rainfall(shaded)

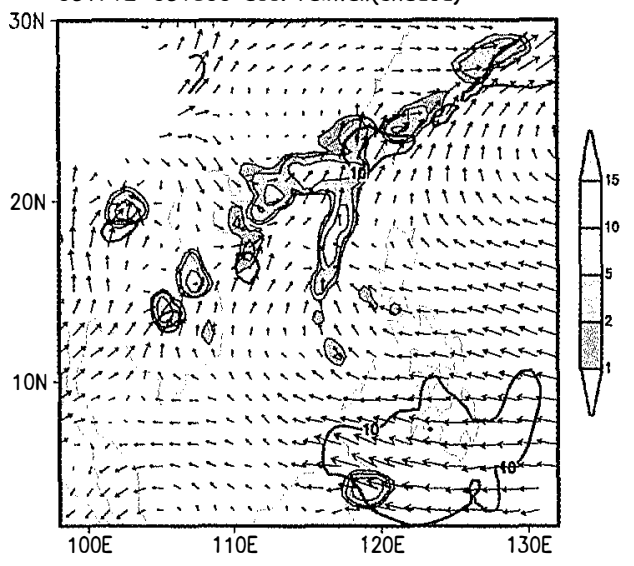

$051812850 \mathrm{hPo}$

(C) $\gg$ wind(vector) \& isotoch(contour) 051800 051812 occ. rainfall(shaded)

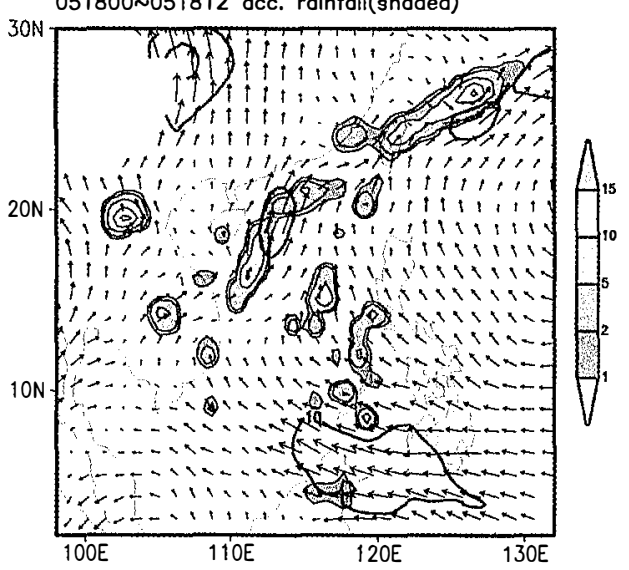

$051800200 \mathrm{hPo}$ wind(vector)

(b) 051712 051800 acc. rainfall(contour) 051712 051800 mean 925hPo conv.(shaded)

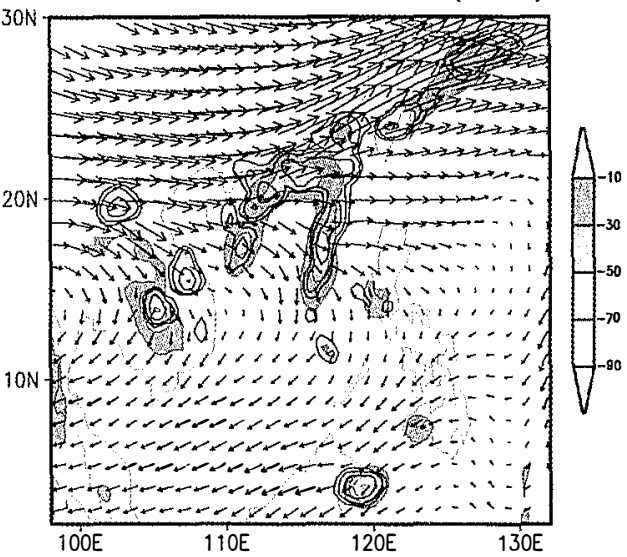

051812 200hPo wind(vector)

(d) 051800 051812 acc. rainfoll(contour) 051800 051812 mean 925hPo conv.(shoded)

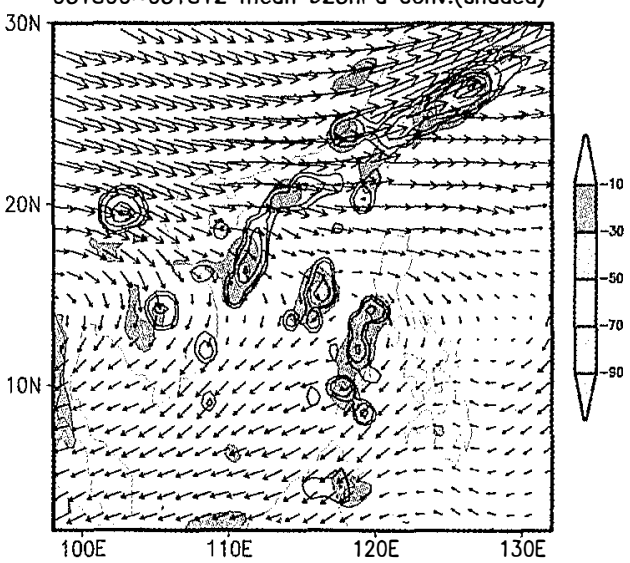

Fig. 7. Coarse domain CNTL simulations. a) accumulated 12-hour precipitation (shaded) and $850 \mathrm{hPa}$ wind vector and isotach (grey thick line) at the last hour of time period 5/17/12Z 5/18/00Z, b) accumulated 12-hour precipitation (thin line), mean $925 \mathrm{hPa}$ convergence (shaded), and $200 \mathrm{hPa}$ wind vector at the last hour of the same period as in a), c) same as in a) except for time period 5/18/00Z 5/18/12Z, d) same as in c) except for time period 5/18/00Z 5/18/12Z. Contour interval of isotachs is $5 \mathrm{~m} \mathrm{~s}^{-1}$, values less than $10 \mathrm{~m} \mathrm{~s}^{-1}$ are not shown. Precipitation is shaded at intervals $1,5,10,15,20$, and $25 \mathrm{~cm}$ as indicated by the bar chart at the right side of the panel. Convergence is shaded at an interval of $10 \times 10^{-6} \mathrm{~s}^{-1}$ as indicated by the bar chart at the right side of the panel. 


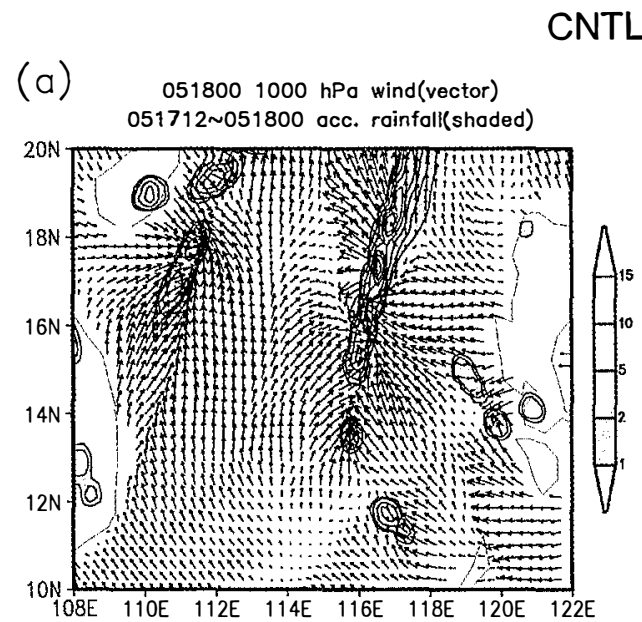

(b)

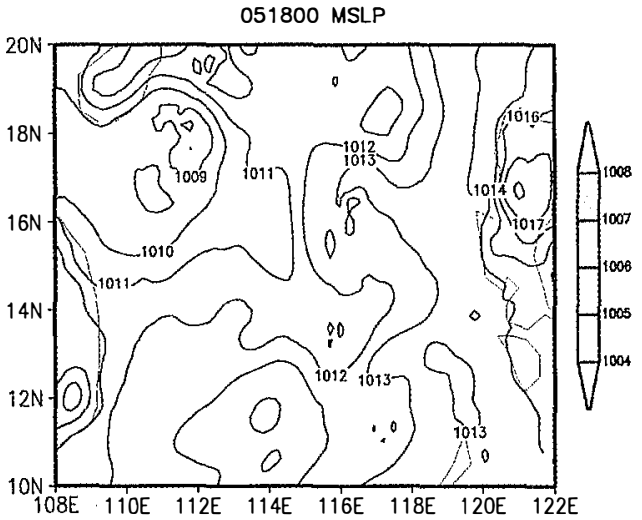

(c)

$0518121000 \mathrm{hPa}$ wind(vector) 051800 051812 acc. rainfall(shaded)

(d)
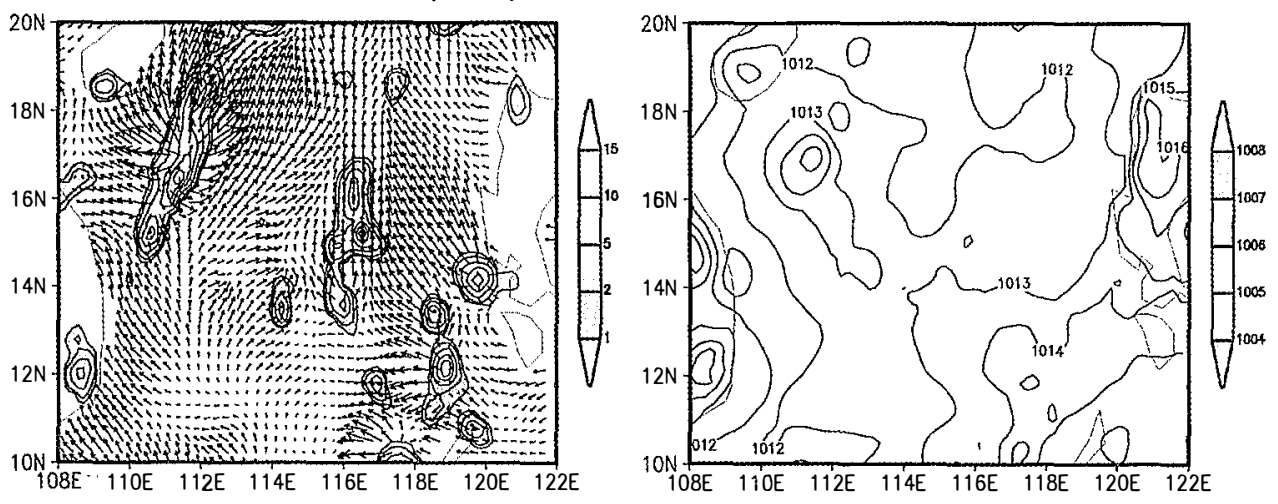

Fig. 8. Fine domain CNTL simulations. a) accumulated 12-hour precipitation (shaded) and $1000 \mathrm{hPa}$ wind vector at the last hour of time period 5/17/ $12 Z \sim 5 / 18 / 00 Z$, b) sea level pressure at the last hour of the same period as in a), c) same as in a) except for time period 5/18/00Z 5/18/12Z, d) same as in c) except for time period 5/18/00Z 5/18/12Z. Precipitation is shaded at intervals $1,5,10,15,20$, and $25 \mathrm{~cm}$ as indicated by the bar chart at the right side of the panel. Sea level pressure is contoured at an interval of 1 $\mathrm{hPa}$.

ence of mesoscale circulation forcing is more important.

\subsection{The Second Sub-period - A Transition Period}

During the second sub-period, the major feature of the MCS development is that the frontal clouds along the coast of southern China propagated eastward and dissipated, and the MCSs over the northern SCS gradually organized into a convective cloud band oriented in the north- 
(a) CNTL

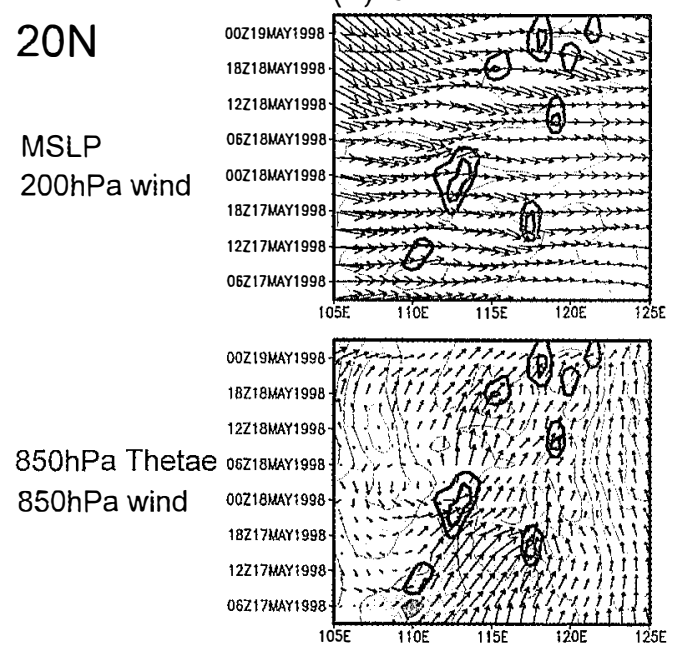

(b) CNTL
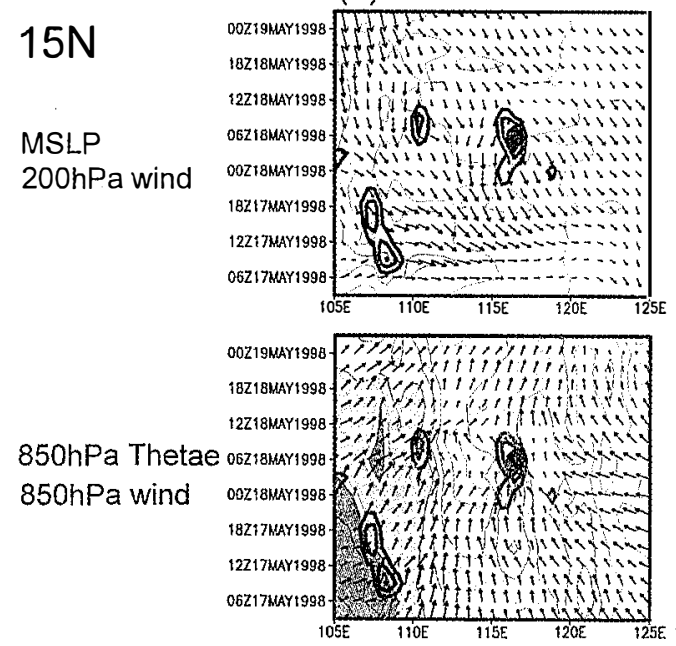

(c) NLHR
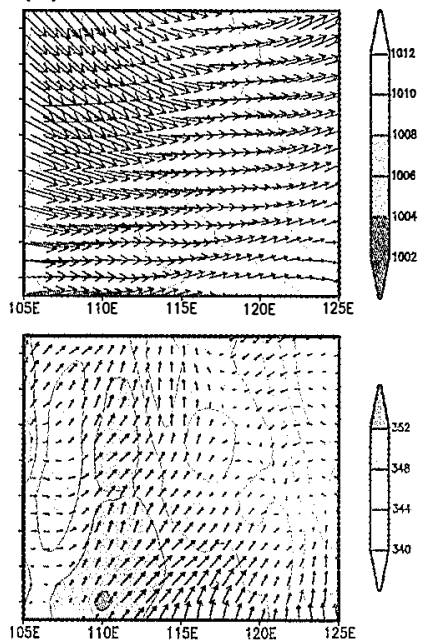

(d) NLHR
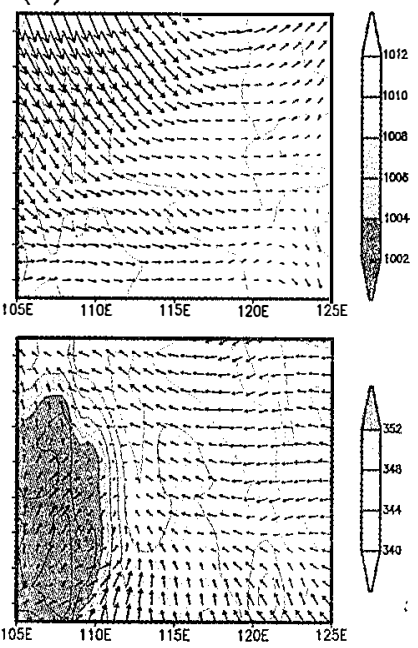

Fig. 9. Time-longitude cross sections along latitudes $20^{\circ} \mathrm{N}(\mathrm{a}, \mathrm{c})$ and $15^{\circ} \mathrm{N}(\mathrm{b}, \mathrm{d})$ of coarse domain CNTL ( $a, b)$ and NLHR (c, d) simulations for time period 0000UTC 17 May 0600UTC 19 May. In each panel, the upper diagram shows sea level pressure (shaded) and $200 \mathrm{hPa}$ wind vectors, the lower diagram shows $850 \mathrm{hPa}$ equivalent potential temperature (shaded) and wind vectors. Sea level pressure and equivalent potential temperature are shaded at intervals $2 \mathrm{hPa}$ and $4 \mathrm{~K}$, respectively, as indicated by the bar charts at the right side of the diagrams. The white thick lines represent $1008 \mathrm{hPa}$ and $352 \mathrm{~K}$, respectively. The thick black lines shown in the CNTL simulations $(a, b)$ are contour lines of hourly accumulated precipitation with an interval of $1 \mathrm{~cm}$. 
west-southeast direction (Figs. 2f, g, h). The coarse domain accumulated precipitation analyses (Fig. 10) show, over the northeastern SCS and the Bashi Channel, an organized convective cloud band detaching from the frontal cloud band. Within the 12 hours from 1200UTC 19 May to 0000UTC 20 May (Fig. 10a), along $20^{\circ} \mathrm{N}$ latitude line, the $850 \mathrm{hPa}$ westerly wind component entering the MCS area from the west increased, and the low-level south inflows of MCSs occurring over the northwestern and the northeastern SCS were coming from the west and the east, respectively. However, during the period from 0000UTC 20 May to 1200UTC 20 May (Fig. 10c), the south inflow of the MCSs occurring over the northern SCS was mainly southwesterly, coming from the west. A weak low-level cyclonic circulation was found in the neighborhood of the MCSs, and the $850 \mathrm{hPa}$ winds over the central-southern SCS were getting weaker. The variation of wind field depicts the eastward retreat of the subtropical high and the propagation of the southwesterly flow, which exerts direct influences on the MCS development over the SCS. In addition, strong southwesterly winds appeared in the southern China region. This is the southwesterly flow ahead of the low pressure system $\mathbf{L}$, which will be further discussed later. In Figs. 10b, d, the $925 \mathrm{hPa}$ convergent zones coincided with the locations of MCSs. In the upper troposphere, the $200 \mathrm{hPa}$ winds maintained a westerly-northwesterly diffluent flow pattern and the outflows from the MCSs were almost toward the east.

In Fig. 1la, MCSs developed over the northern Philippines and to the east of Hainan island during 0600UTC 21 May 1800UTC 21 May. This corresponds well with the MCSs shown by satellite image in Fig. 2i. In the following 12 hours (Fig. 11c), these MCSs gradually organized into a northwest-southeast oriented cloud band, which is indicated by MCS $\mathbf{H}$ in Fig. 2j. As compared with Figs. 10a, c, during the time periods shown in Figs. 11 a, c, the lowlevel flows over the northern SCS were nearly from the west, while over the southern SCS flows were mainly from the south and the west. Figure 11 a depicts a cyclonic circulation accompanied with the MCS near the northern Philippines and weak northeasterly winds between the northern Bashi Channel and the Taiwan Strait. Twelve hours later (Fig. 11c), with the MCS development, a cyclonic circulation of considerable horizontal extent was observed in the northern SCS region, which reveals a close link between the MCS development and the low pressure center shown in Fig. 1d. In response to the MCS development, the southward diffluent wind component became more evident in the upper troposphere (Figs. 11b, d). Another feature of the MCS development during this sub-period is worth mentioning. On the 850 $\mathrm{hPa}$ isobaric surface, weak northeasterly winds (Fig. 11) with low pressure and low equivalent potential temperature (not shown) were of ten found to the northeast of a newly formed MCS. The northeasterly wind brings in cold air from the north, which is anticipated to increase the low-level instability and favor the MCS development.

The fine domain CNTL simulations show similar mesoscale features, as presented in the first sub-period. During 1200UTC 19 May 0000UTC 20 May the MCS to the east of Hainan island was accompanied with obvious low-level convergence, it therefore continued to grow. Over the northern SCS near the Philippines, the flow showed relatively weak convergence, only sporadic clouds were found to grow later on (not shown). However, the outflows of these clouds interacted with the environmental winds and did initiate new convections. The simulation for the period 0600UTC 21 May 1800UTC 21 May reveals that the MCS, which developed near the northern Philippines, comprises several strong convective cells (Fig. 12a). Strong 


\section{CNTL-DO1}

$052000850 \mathrm{hPa}$

(a) >>wind(vector) \& isotach(contour) $051912 \sim 052000$ acc. rainfall(shaded)

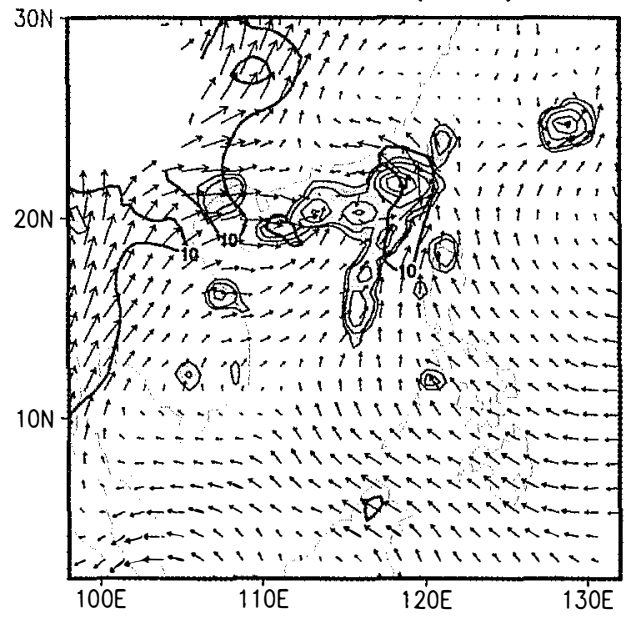

$052012850 \mathrm{hPa}$

(C) $\gg>$ wind(vector) \& isotach(contour) 052000 052012 acc. rainfall(shaded)

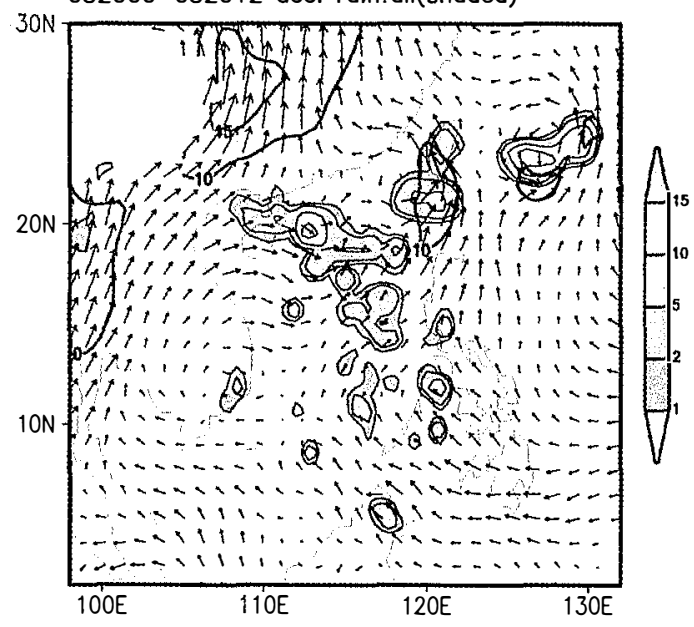

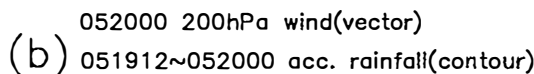
051912 052000 mean 925hPa conv.(shaded)

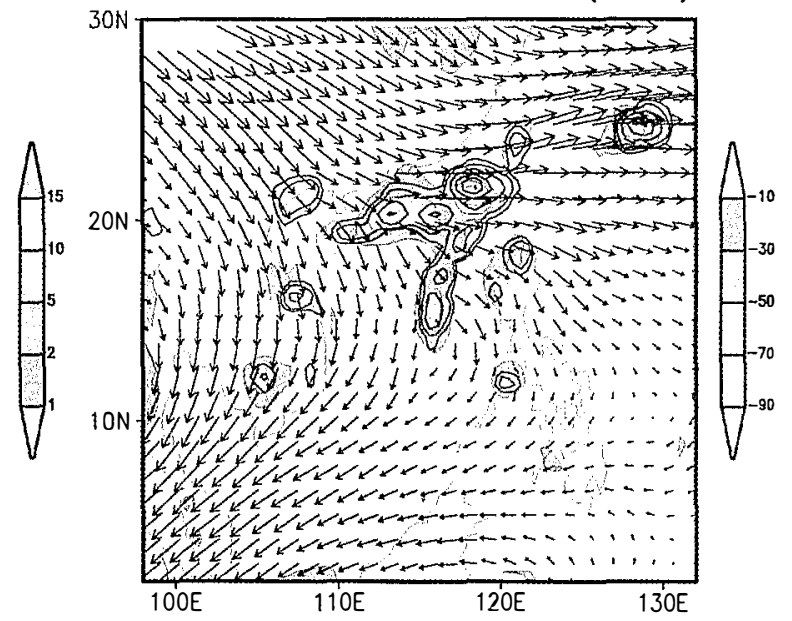
$052012200 \mathrm{hPa}$ wind(vector)

(d) 052000 052012 acc. rainfall(contour) 052000 052012 mean 925hPa conv.(shaded)

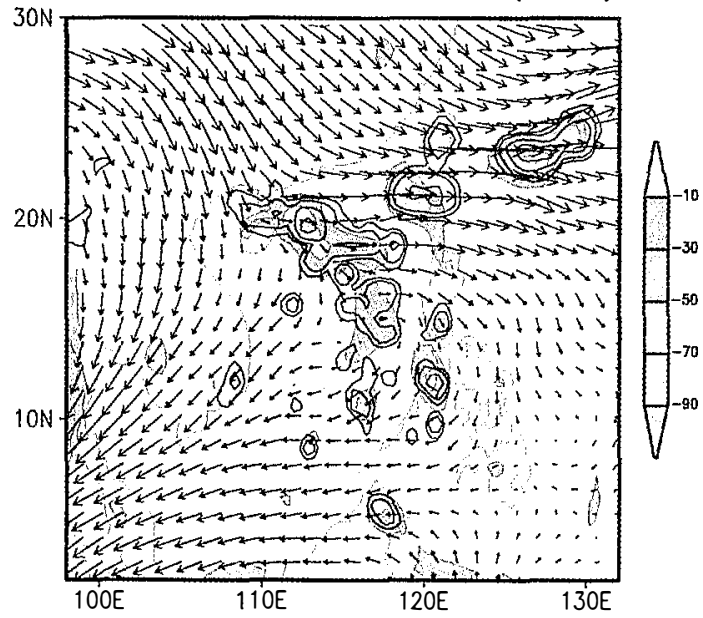

Fig. 10. Same as Fig. 7 except for time periods 5/19/12Z 5/20/00Z (a, b) and 5/ 20/00Z 5/20/12Z (c, d).

low-level convergences were found on the west and the south flanks of the MCS. Therefore, new MCSs (indicated by $\mathbf{H}$ in Fig. $2 \mathrm{j}$ ) formed and developed to the southwest of the former MCS along the local mesoscale convergent zones (Fig. 12c). In association with the MCS development, decreasing simulated sea level pressure was first found near the northern Philippines (Fig. 12b), and then extending over nearly the entire northern SCS (Fig. 12d). The simu- 
lated results suggest that MCS development is capable of producing large-area low pressure zone, not just small local low centers. In a numerical simulation of a long-lived MCS development, Zhang and Bao (1996a, b) also found that convection has significant impact on the development of a midlatitude trough.

In contrast to the sporadic feature of MCS development during the first sub-period, the simulated results of the CNTL runs reveal that MCSs occurring in the second sub-period are rather organized, the low pressure centers are more evident with larger spatial extent, and the $850 \mathrm{hPa}$ southwesterly winds are stronger and more widely spread. However, without latent heat release, the NLHR runs are not able to produce similar features (not shown). For the LTER runs, the simulated results over the SCS are similar to those of the CNTL runs (not shown). As mentioned before, the terrain effect is only significant for local convections over land.

Time-sequence results show that organized MCSs were mainly occurring over the northern SCS during the period from 1200UTC 19 May to 0000UTC 21 May and exhibited mesoscale characteristics similar to those depicted in the first sub-period (not shown). After 21 May, significant decrease of sea level pressure was noted extensively over the SCS, and the increase of westerly wind components was also very pronounced over the southern SCS (Figs. 13a, b). In the upper-level, the flow over the northern SCS changed gradually from westerly to northerly, while the outflow associated with the MCSs occurring over the southern SCS showed diffluent pattern obviously. The simulated results of the NLHR runs presented in Figs. 13c, d, however, didn't show extensive decreasing of sea level pressure, intensifying of westerly wind component in the southern SCS region, and changing of upper-level flow. This indicates that the convective latent heat release plays an important role in the fall of sea level pressure and the enhancement of westerly wind over the SCS. Again, this is consistent with the findings of Zhang and Bao (1996a, b). Another numerical study of MCS development on a Mei-Yu front by Chen et al. (1998a) also demonstrated the convective enhancement of low-level jet in the southern periphery of a MCS.

Over the northern SCS along latitude $20^{\circ} \mathrm{N}$, the simulated results of the NLHR runs (Fig. 13c) didn't show low $850 \mathrm{hPa}$ equivalent potential temperature to the east of MCSs similar to that of the CNTL runs (Fig. 13a). During the time period shown in Fig. 13, the sky was virtually clear in the vicinity of Taiwan and the Bashi Channel. The differences between CNTL and NLHR runs suggest that the northeasterly wind and cold dry air to the north of MCS $\mathbf{H}$ (Figs. $2 \mathrm{j}, \mathrm{k}$ ) could be due to local intensifying of northerly wind components caused by low-level convergence of MCSs and the channel effect of the Taiwan Strait.

\subsection{The Third Sub-period - Mesoscale Convective Activities}

The third sub-period is a period with MCSs developing over the entire SCS. During 1200UTC 23 May 0000UTC 24 May, MCSs near Hainan island developed under the favorable condition of low-level confluence of strong northerly and westerly winds (Fig. 14a). The MCSs near the Philippines were accompanied by westerly winds to their west, but the strong southwesterly winds were limited to the southern flanks of MCSs only. The local feature of southwesterly winds could be an evidence of the accelerating effect as a result of the MCS 
$052118850 \mathrm{hPo}$

(a) >>wind(vector) \& isotoch(contour) 052106 052118 occ. rainfall(shoded)

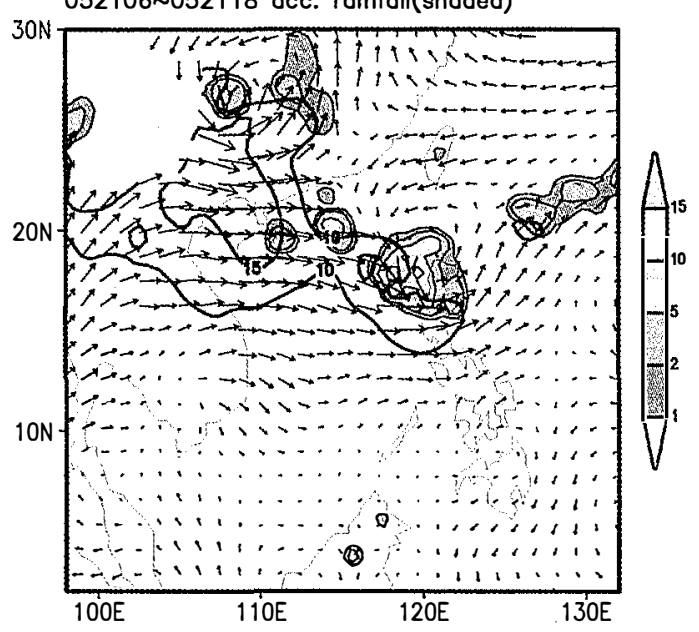

(C) $>>$ wind(vector) \& isotoch(contour) 052118 052206 occ. rainfall(shoded)

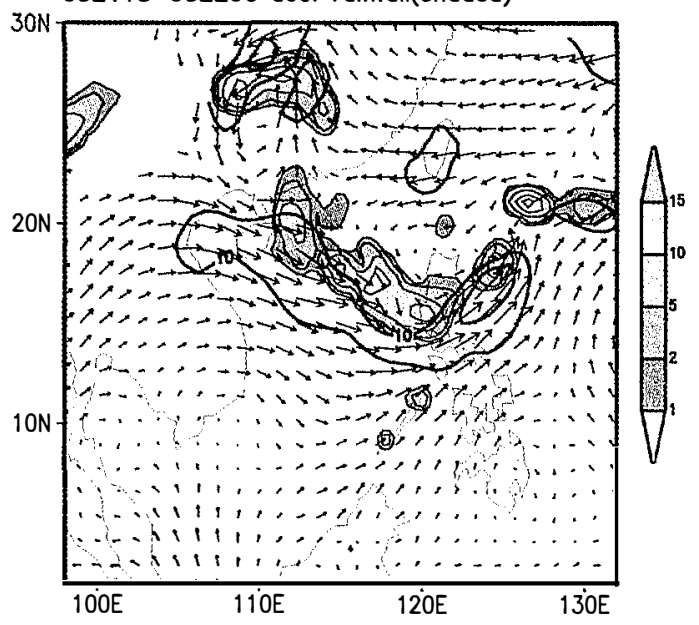

\section{CNTL-DO1}

$052118200 \mathrm{hPo}$ wind(vector)

(b) $052106 \sim 052118$ acc. rainfall(contour) 052106 052118 mean 925hPa conv.(shoded)

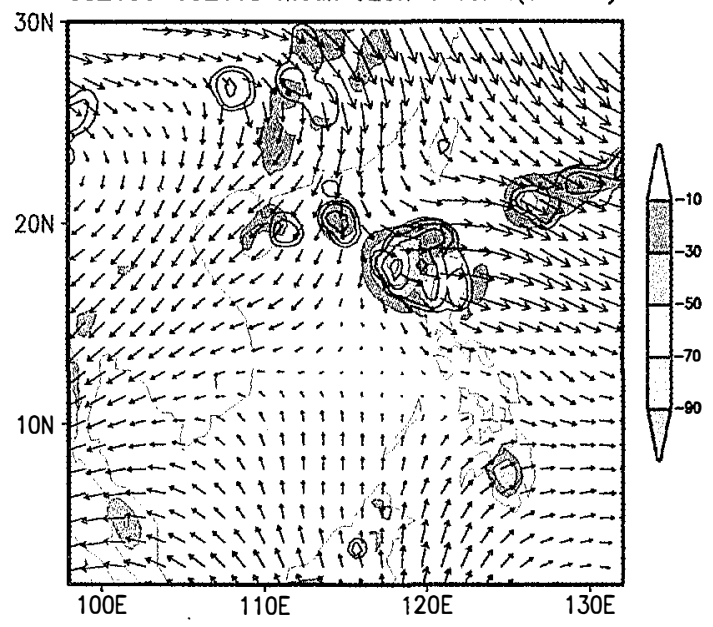

$052206200 \mathrm{hPo}$ wind(vector)

(d) $052118 \sim 052206$ occ. roinfoll(contour) 052118 052206 mean 925hPo conv.(shoded)

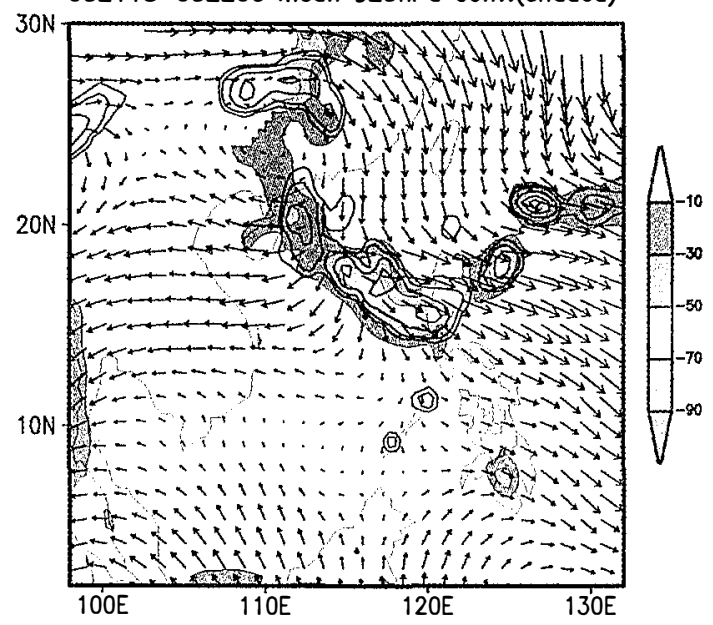

Fig. 11. Same as Fig. 7 except for time periods 5/21/06Z 5/21/18Z (a, b) and 5/ 21/18Z 5/22/06Z (c, d).

development. In the next 12 hours, MCSs over the northern and the southern SCS moved closer together (Fig. 14c). These MCSs occurring in this sub-period were all accompanied with obvious low-level convergence and upper-level divergence or diffluence (Figs. 14b, d). The upper-level diffluent outflows of the southern MCSs are particularly discernible, and conform with the anticipated southward development of MCS over the central and the southern 


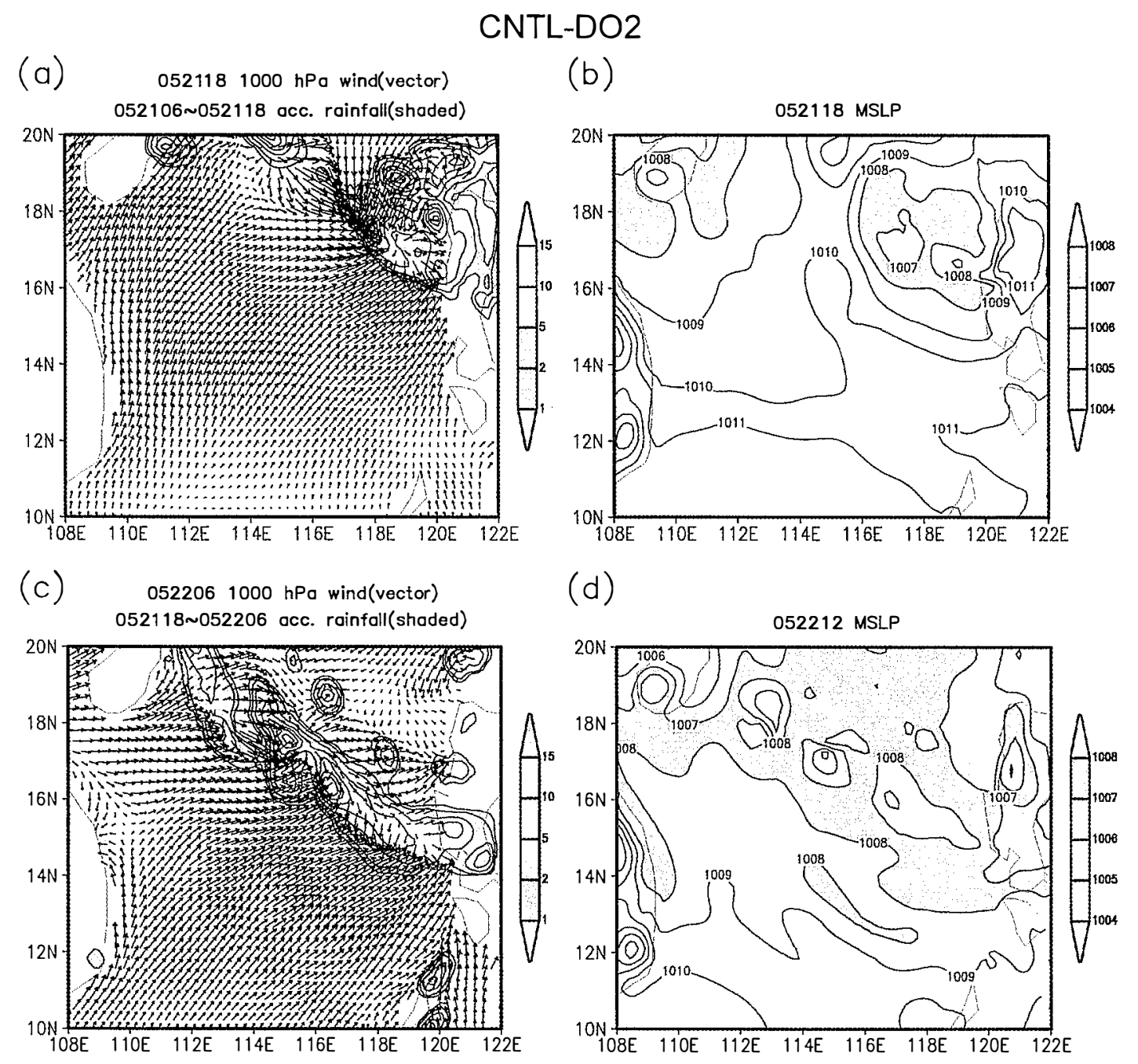

Fig. 12. Same as Fig. 8 except for time periods 5/21/06Z 5/21/18Z (a, b) and 5/ 21/18Z 5/22/06Z (c, d).

SCS. A major change, as compared with the second sub-period, is that the upper-level northerly wind crossing $20^{\circ} \mathrm{N}$ became much weaker.

Figure 15 shows the fine domain CNTL simulations; the low-level outflows as a result of the MCS development near the Philippines during the time period 1200UTC 23 May 0000UTC 24 May (Fig. 15a) led to vigorous convections near the southern flanks of the preceding MCSs in the next 12 hours (Fig. 15c). Similar MCS developments also occurred near Hainan island. This chain development of MCS persisted for a few days over the SCS after the monsoon onset (not shown). As shown in Figs. 15b, d, high sea level pressure is found in association with the descending outflows. Over the northern SCS, on the average, the sea level pressure decreases appreciably during the 12-h period. 
(a) CNTL

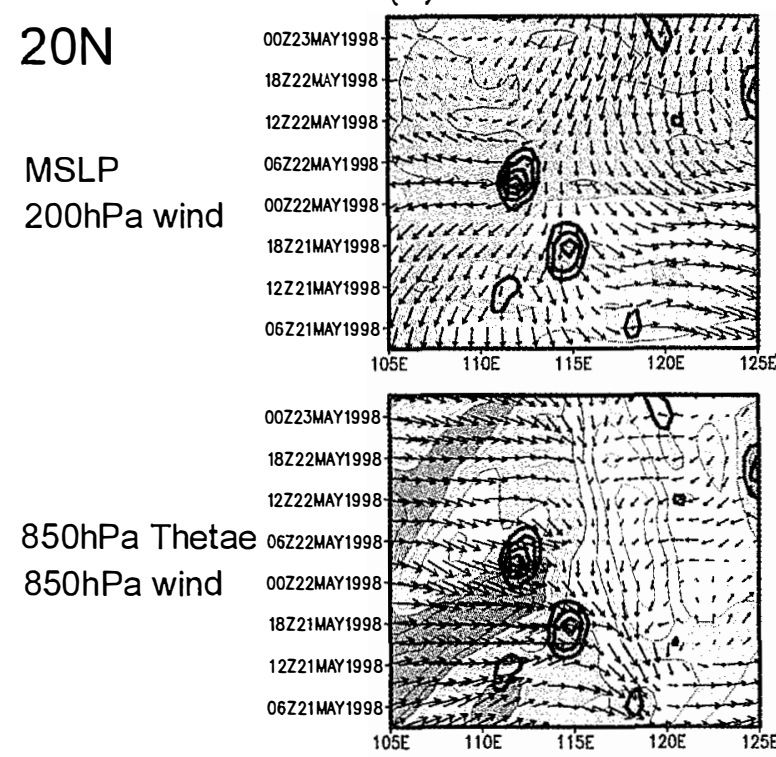

(b) CNTL

$15 \mathrm{~N}$
MSLP
$200 \mathrm{hPa}$ wind

850hPa Thetae 06z22may 1998 $850 h P a$ wind 00z22MAY1998 18Z21MAY1998 12Z21MAY 1998 06Z21MAY1998
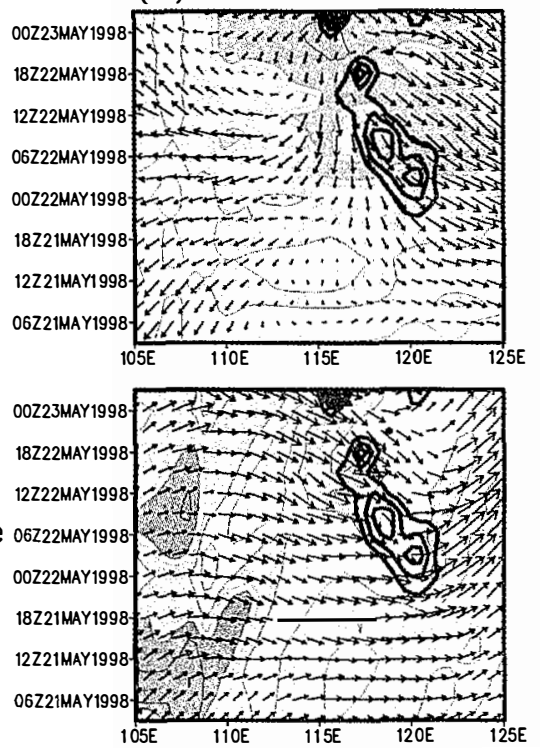

(d) NLHR

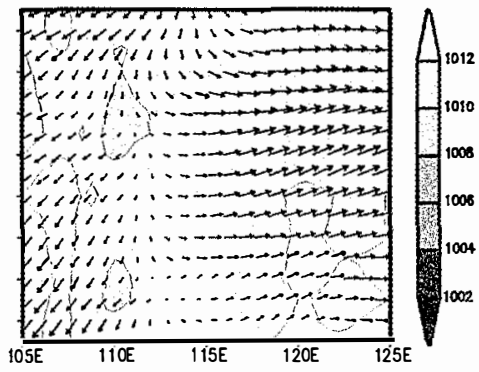

(c) NLHR
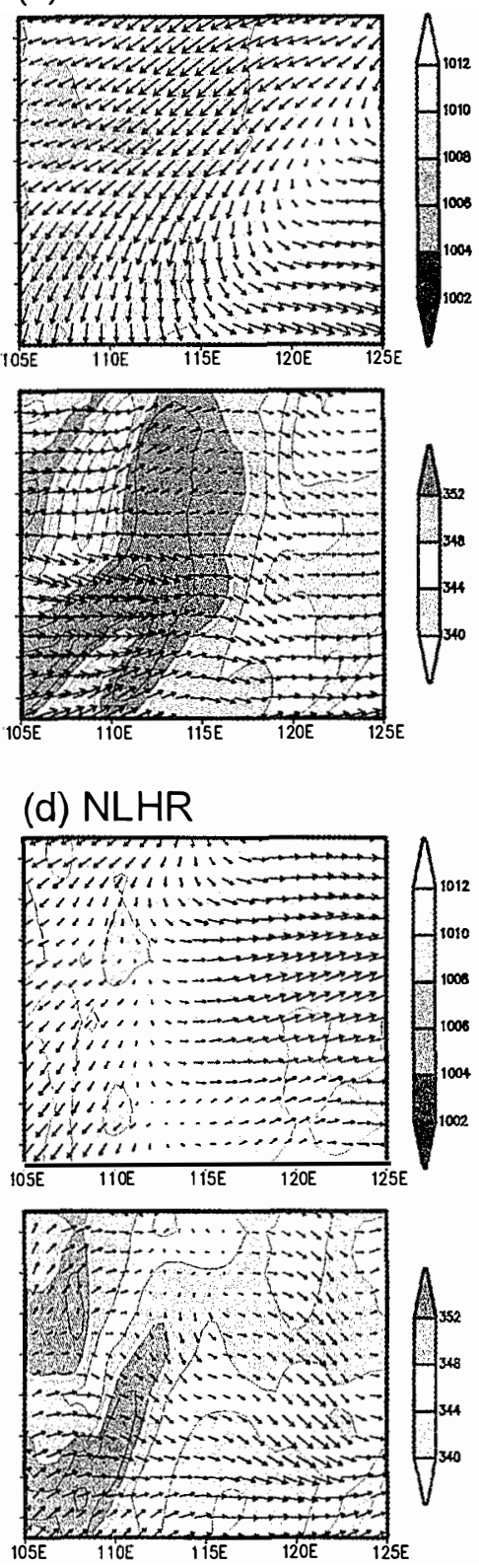

Fig. 13. Same as Fig. 9 except for time period 0000UTC 21 May 0600UTC 23 May. 


\section{CNTL-DO1}

$052400850 \mathrm{hPa}$

(a) >>wind(vector) \& isotoch(contour)

$052312 \sim 052400$ acc. rainfall(shaded)

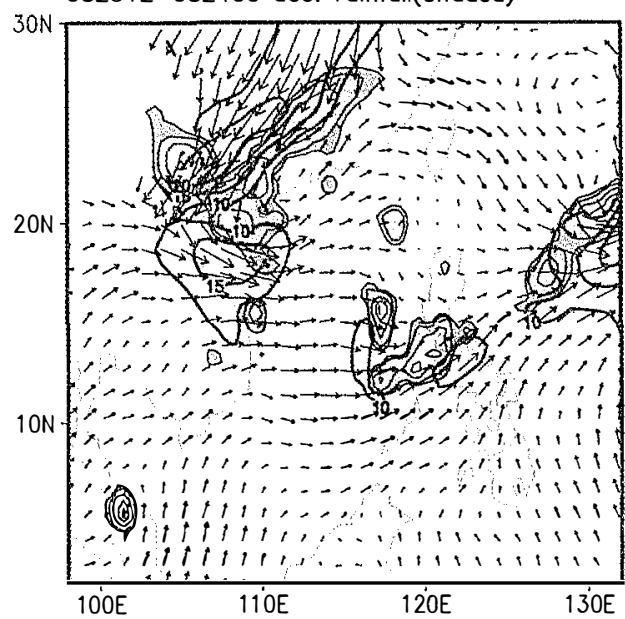

$052412850 \mathrm{hPa}$

(C) > wind(vector) \& isotach(contour) 052400 052412 acc. rainfall(shaded)
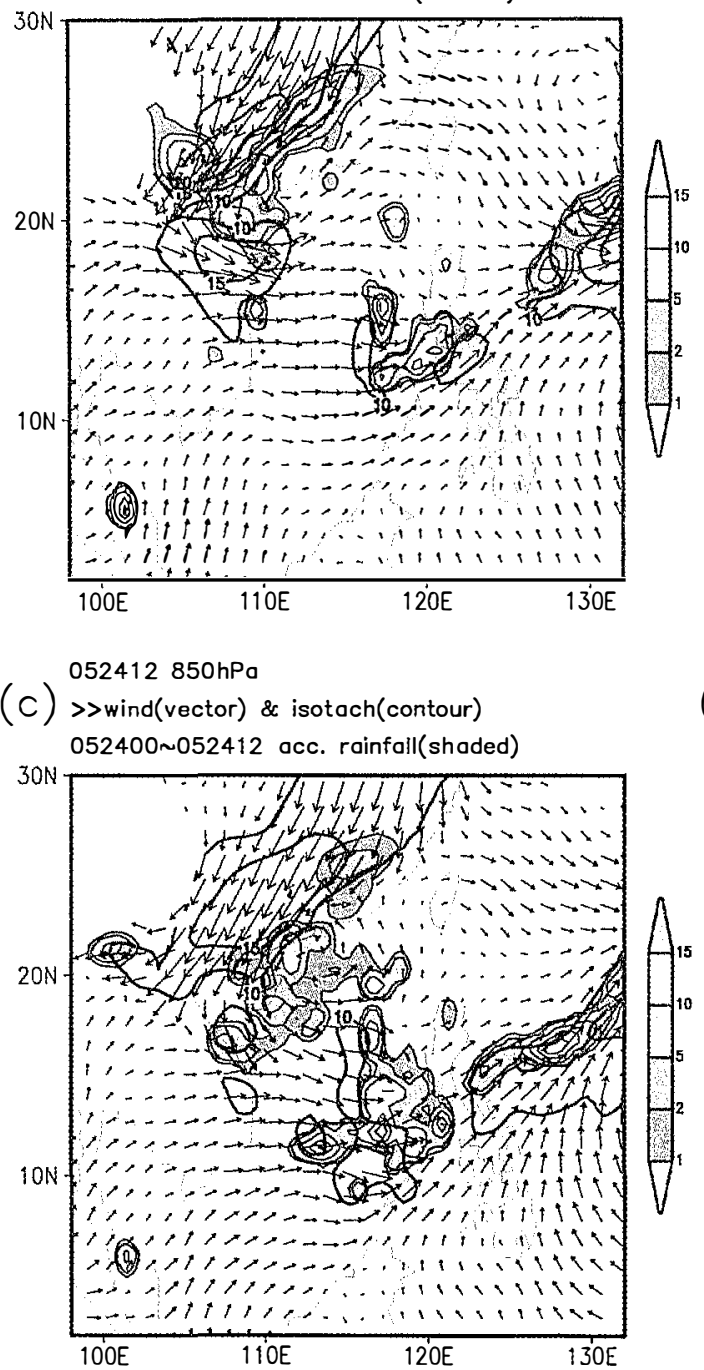

$052400200 \mathrm{hPa}$ wind(vector)

(b) 052312 052400 acc. rainfall(contour) 052312 052400 mean 925hPa conv.(shaded)

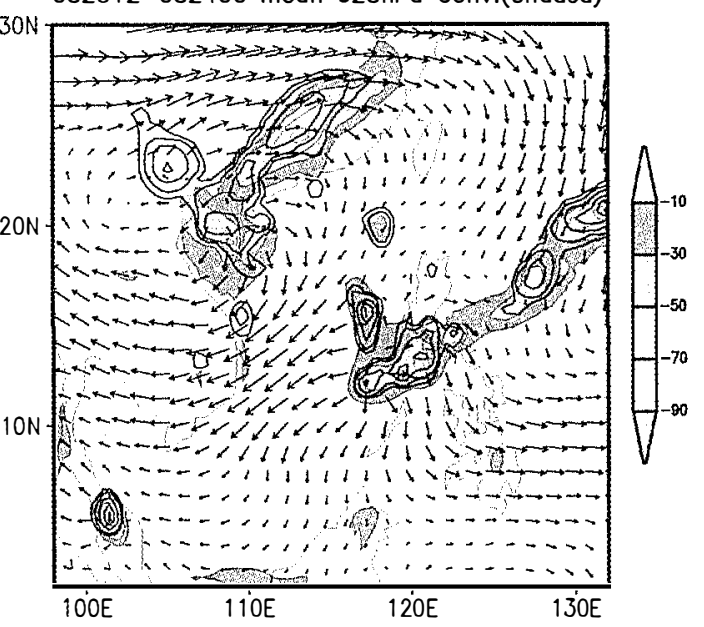

$052412200 \mathrm{hPa}$ wind(vector)

(d) 052400 052412 acc. rainfall(contour)

052400 052412 mean 925hPa conv.(shaded)

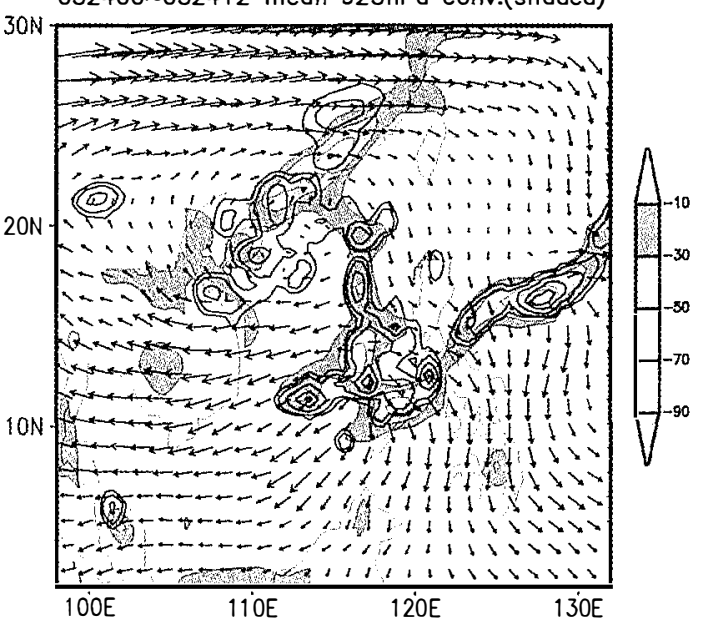

Fig. 14. Same as Fig. 7 except for time periods 5/23/12Z 5/24/00Z (a, b) and 5/ 24/00Z 5/24/12Z (c, d). 
Displayed in Fig. 16 are time-sequence coarse-domain simulations for the time period from 0600UTC 23 May to 0000UTC 25 May. The $850 \mathrm{hPa}$ equivalent potential temperature of CNTL runs (Figs. 16a, b) exhibits temporarily increasing and then decreasing corresponding to the MCS developing and decaying stage, respectively. The lowering of sea level pressure and intensifying of $850 \mathrm{hPa}$ southwesterly wind are also very evident over the SCS. These important features, however, were not seen in the NLHR runs (Figs. 16c, d). After 1800UTC 23 May, along latitude $20^{\circ} \mathrm{N}$ in the longitude range $105^{\circ} \sim 115^{\circ} \mathrm{E}$, the $850 \mathrm{hPa}$ northerly winds of the NLHR runs were much weaker than those of the CNTL runs. The strengthening of northerly winds is partly attributed to the southward propagation of high pressure, but the differences between CNTL and NLHR runs also indicate the importance of the latent heat effect.

Summarized from the simulated results of the three sub-periods, the monsoon trough and regional low pressure center seem to be constructed progressively from the local pressure and wind disturbances associated with the MCS development. The circulation pattern over the SCS also changes gradually from local small scale disturbances into a flow regime of synoptic-scale feature. This reveals the multi-scale characteristics of monsoon evolution over the SCS. The NLHR simulations of both coarse and fine domains for the three sub-periods all show similar conclusions that the southwesterly flow and monsoon trough would not develop successfully over the SCS without the effect of latent heat release.

\subsection{Relationship Between the Surface Low Pressure System and the Convective Activi- ties over the SCS}

The surface low pressure center as indicated by $\mathbf{L}$ in Fig. 1 exhibited different characteristics during the monsoon evolution. In the early stage, its formation and southward propagation were occurring mainly in the midlatitude baroclinic zone over land. In the later stage, the low pressure center moved southeastward over the ocean where observations are virtually void. Benefited by the model simulation, we are able to examine the evolution of the low pressure center over the northern SCS and its relationship to the development of monsoon trough and convective activities over the SCS.

The coarse-domain simulations of sea level pressure and 6-hour accumulated precipitation for time period 0000UTC 22 May 0600UTC 24 May are shown in Fig. 17 with an interval of 6 hours. While $\mathbf{L}$ was moving southward over land, the low pressure center coincided with the distribution of MCS pretty well. During 1200UTC 1800UTC on 22 May, the local low pressure center near Hainan island weakened considerably when the MCS over the northern SCS dissipated, which points to an evidence of the mesoscale mass adjustment in association with the MCS development. After 1200UTC on 23 May, L moved southward over the Bay of Tongkin and was further maintained as a local low pressure center in company with the MCS development over the SCS. While $\mathbf{L}$ was over land, the NLHR runs (not shown) can still simulate the southward movement of the low pressure center except with weaker strength. However, the low pressure center disappeared immediately when it moved over ocean, suggesting the critical role of the latent heat effect in the maintenance of the low pressure center over the SCS. The convective impact on the evolution of the low pressure system is quite 


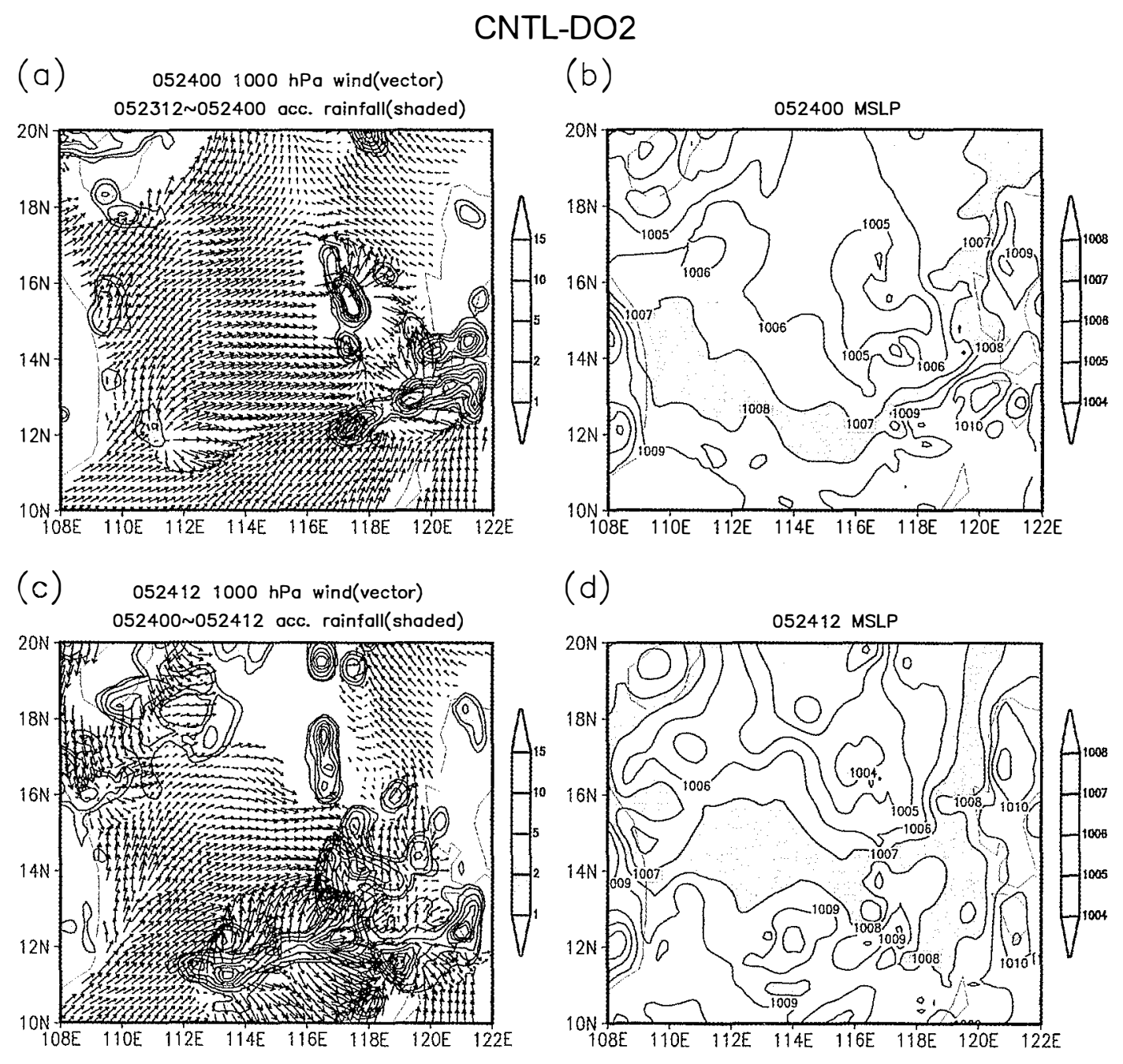

Fig. 15. Same as Fig. 8 except for time periods 5/23/12Z 5/24/00Z (a, b) and 5/ 24/00Z 5/24/12Z (c, d).

similar to a case study conducted by Zhang and Bao (1996a, b) on the oceanic cyclogenesis as induced by a MCS moving offshore.

\section{CONCLUSIONS}

In this study, PSU/NCAR MM5 was used to simulate the evolution of the 1998 East Asian summer monsoon onset. Simulation outputs were further utilized to study the MCS development and its interactions with the synoptic/large-scale environment over the SCS. Prior to the monsoon onset and in the early stage of onset, frontal clouds and southwesterly winds 
(a) CNTL

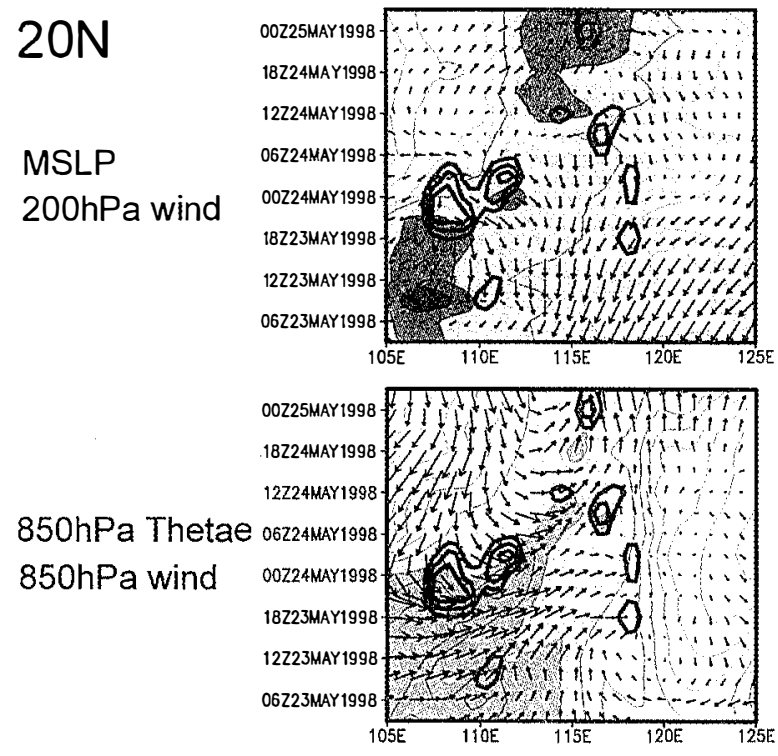

(b) CNTL

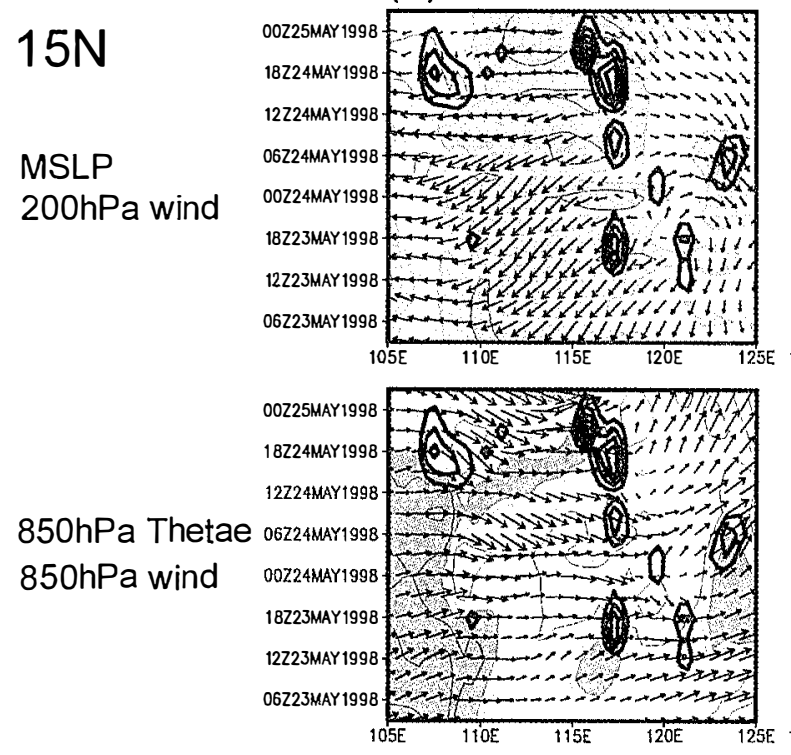

(c) NLHR
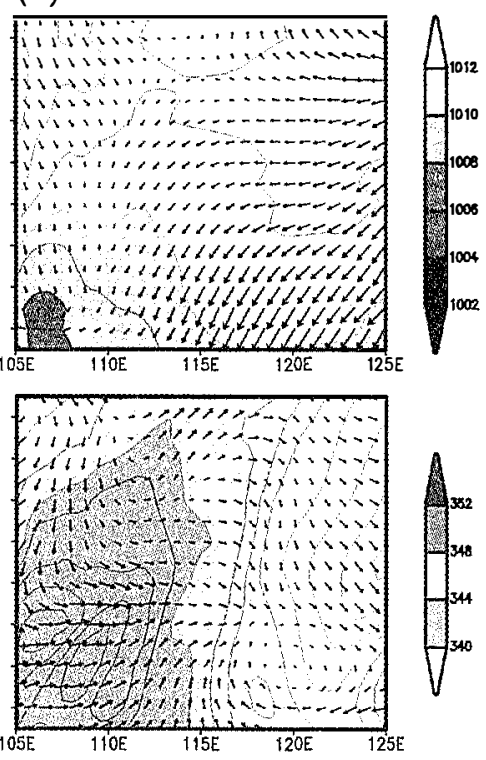

(d) NLHR
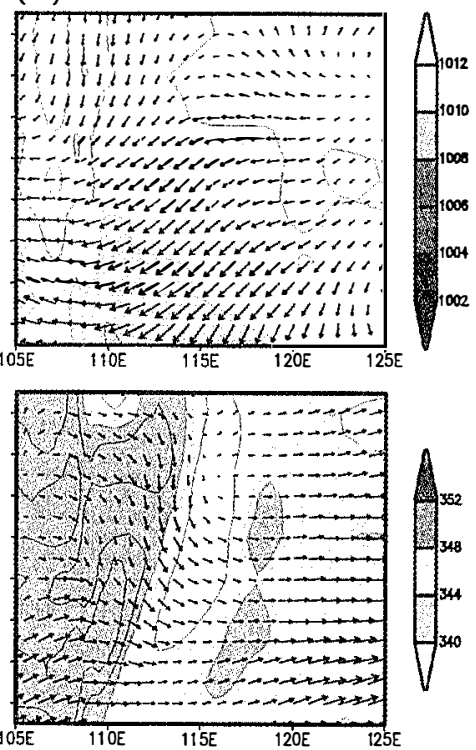

Fig. 16. Same as Fig. 9 except for time period 0000UTC 23 May 0600UTC 25 May. 
developed along the coast of southern China and over the northern SCS due to southward intrusion of midlatitude weather systems. The frontal clouds grew in a region with low-level southwesterly confluence north of the subtropical Pacific high ridge and upper-level northwesterly diffluence north of the South Asian anticyclonic ridge. In the later stage of onset, extensive convections developed over the central-southern SCS. In the SCS region, the surface pressure gradient increased apparently in the north-south direction, southwesterly winds of tropical origin prevailed in the lower troposphere with upper-level northeasterly diffluence occurring south of the anticyclonic ridge. Distinct changes of flow regime occurred in the lower and upper levels during the monsoon onset. Under favorable large-scale environment, a burst of intense convections over the central-southern SCS seems to be led by a succession of MCS development occurring within the frontal zone over the northern SCS. During the period 17-19 May, a frontal cloud band persisted over the northern SCS with intermittent development of MCSs over the ocean between Hainan and Tongsha islands. The low-level convergence associated with MCSs and the wind disturbances caused by the northwesterly descending outflow of dissipating MCSs could play the triggering role in the formation of a new MCS. Thus, the MCS development over the central-southern SCS after 21 May could not be unrelated to the convective activities in the northern SCS region. Although the MCSs over the central-southern SCS were developing in a favorable synoptic low-level confluent environment, the time sequence of satellite cloud images depict that their developments were closely related to the dissipation of MCSs over the northern SCS. This also suggests that the convective disturbances resulting within the frontal zone could possibly provide a mesoscale triggering mechanism for the MCS development over the central-southern SCS.

Overall, the MCS development over the SCS is not an independent event, it is a series of multi-scale interactions between the midlatitude and the tropical circulations. The upper-level diffluent flow, the low-level southwesterly confluence as a result of the retreat of the subtropical high, and the moist air with high equivalent potential temperature over the ocean provide the favorable large-scale dynamic and thermodynamic conditions. Synoptic weather systems such as a front can modify the local distribution of wind shear and divergence, and provide an initial dynamic forcing for the development of a MCS. A dissipating MCS may initiate the formation of a new MCS, and several MCSs may merge into a MCS of larger size and longer life. The serial development of MCSs produces mesoscale descending outflows, releases the instability of the atmosphere, and even modifies the large-scale circulation via latent heat release and vertical transport processes.

Model simulated results reveal that, in a warm-moist and unstable atmospheric environment, the mesoscale descending outflow resulting from the MCS development becomes a possible mesoscale triggering mechanism for the formation of a new MCS. The latent heat release in MCS heats the atmosphere, reduces the surface pressure, and therefore enhances the low-level wind convergence and cyclonic circulation. The mesoscale adjustment of wind field and mass field, on the one hand, feeds back and enhances the MCS development or initiates the formation of a new MCS, and the organization of MCSs, on the other hand, integrates the mesoscale disturbances into a synoptic structure and establishs the local monsoon trough. Sensitivity tests depict the effect of latent heat release as it plays a significant role during the monsoon onset process. The terrain effect is significant for local convective activities over land. For 
MSLP(shaded) \& 6 hr acc. rainfall(contour) CNTL-D01
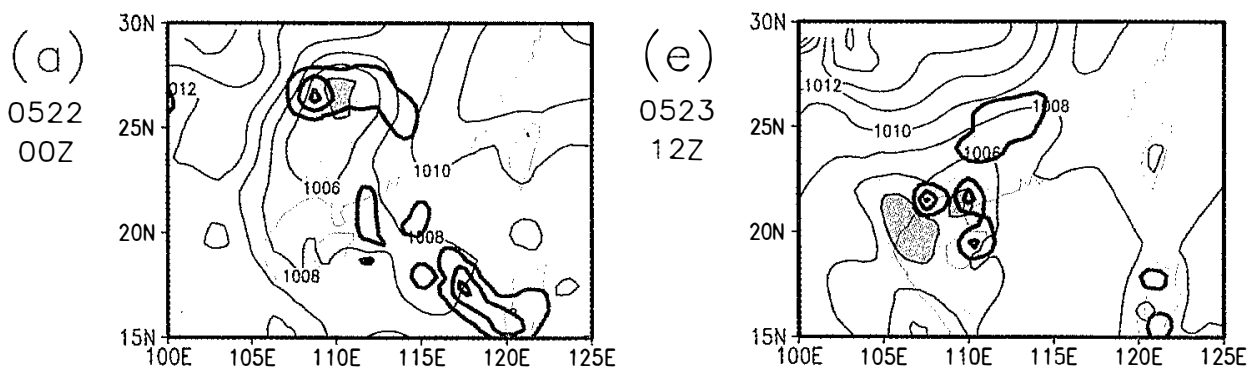

(b)
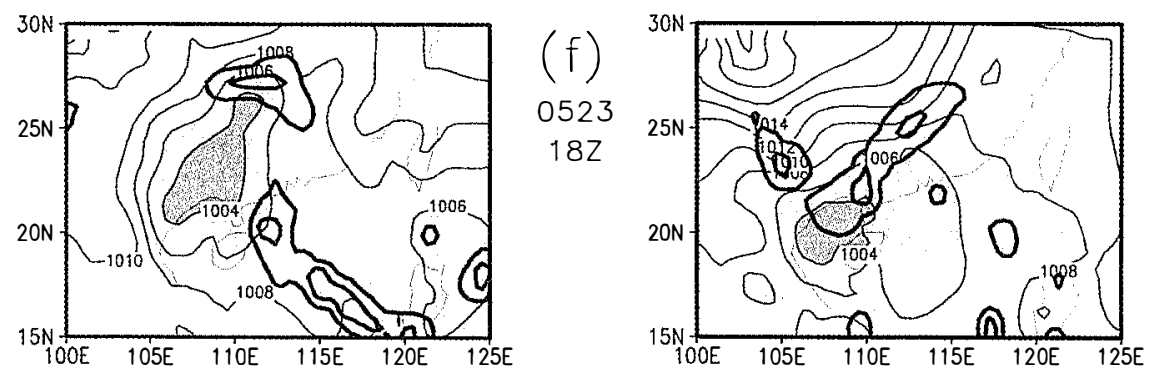

(C)

0522

$12 Z$

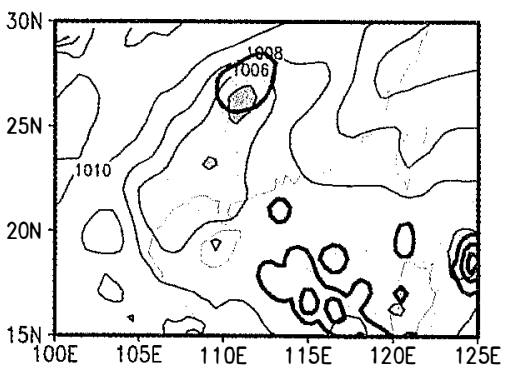

(d)

0522

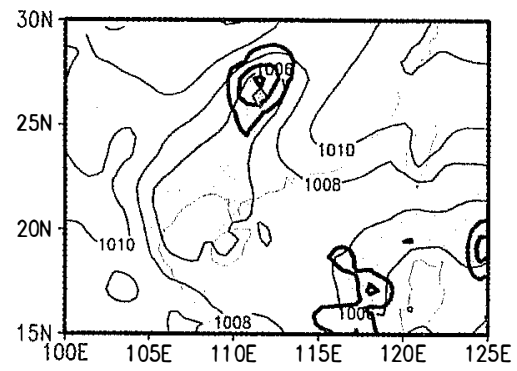

(g)

0524

$00 Z$

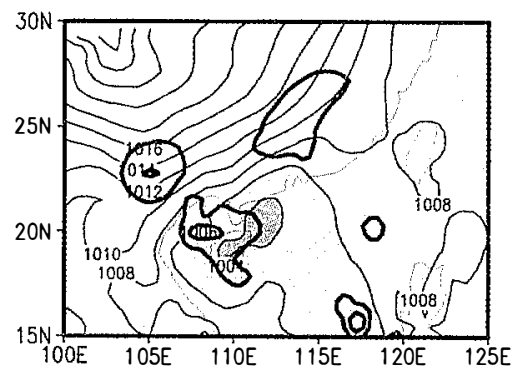

(h)

0524

062

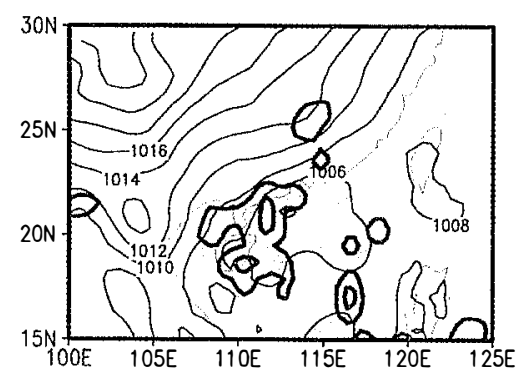

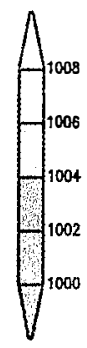

Fig. 17. Coarse domain CNTL simulations of sea level pressure (thin line) and 6hour accumulated precipitation (thick line) for time period 5/22/00Z 5/ 24/06Z with 6-hour interval. Precipitation is contoured at intervals 1,5 , $10,15,20$, and $25 \mathrm{~cm}$. Contour interval of sea level pressure is $2 \mathrm{hPa}$ with values less than $1008 \mathrm{hPa}$ shaded. 
well organized MCSs occurring over the SCS, influence of mesoscale circulation forcing is more important. Without the latent heat release, the monsoon trough cannot form even if the model provides favorable large-scale boundary forcing. Thus, it can be concluded that the establishing of the monsoon trough, lowering of sea level pressure, and increasing of relative vorticity are all closely related to the MCS development. Over the SCS, the MCS development causes mesoscale wind disturbances first, then adjusts the mass field, and finally changes the synoptic environment and establishes the monsoon circulation.

Finally, it should be emphasized that although local low-level wind convergence is an important factor in the formation of an MCS, the fine domain simulation results also indicate that it is still not sufficient to initiate the formation of a new MCS. Other dynamic or thermodynamic triggering mechanisms, such as surface fluxes need to be further studied. In addition, there were frontal passages along the coast of southern China and over the northern SCS before and during the monsoon onset. What are the differences in the role, circulation characteristics, and structure of the fronts occurring before and during the monsoon onset? It seems worthy of further investigation.

Acknowledgements The authors would like to thank Prof. Yihui Ding and an anonymous reviewer for their valuable comments and suggestions. This study is supported by the National Science Council of Taiwan under Grant NSC90-2111-M-008-041. The SCSMEX observations are provided by the SCSMEX project office in Taiwan. The MM5 codes were downloaded from web site at http://www.mmm.ucar.edu/mm5/mm5-home.html, and the NCEP GDAS grid data were obtained from web site at http://www.scd.ucar.edu/dss.

\section{REFERENCES}

Chan, C.-L., Y.-G. Wang, and X.-J. Xu, 2000: Dynamic and thermodynamic characteristics associated with the onset of the 1998 South China Sea summer monsoon. J. Meteor. Soc. Japan, 78, 367-380.

Chang, C.-P., and G. T.-J. Chen, 1995: Tropical circulation associated with southwest monsoon onset and westerly surges over the South China Sea. Mon. Wea. Rev., 123, 32543267.

Chen, C., W.-K. Tao, P.-L. Lin, G.-S. Lai, S.-F. Tseng, and T.-C. Chen Wang, 1998a: The intensification of the low-level jet during the development of mesoscale convective systems on a Mei-Yu front. Mon. Wea. Rev., 126, 349-371.

Chen, S.-J., Y.-H. Kuo, W. Wang, Z.-Y. Tao, and B. Cui, 1998b: A modeling case study of heavy rainstorms along the Mei-Yu front. Mon. Wea. Rev., 126, 2330-2351.

Chen, Y.-L., X.-A. Chen, S. Chen, and Y.-H. Kuo, 1997: A numerical study of the low-level jet during TAMEX IOP 5. Mon. Wea. Rev., 125, 2583-2604.

Ding, Y., and Y. Liu, 2001: Onset and the evolution of the summer monsoon over the South China Sea during SCSMEX field experiment in 1998. J. Meteor. Soc. Japan, 79, 255276.

Fujita, T. T., 1959: Precipitation and cold air production in mesoscale thunderstorm systems. J. Meteor., 16, 454-466. 
Grell, G. A., 1993: Prognostic evaluation of assumptions used by cumulus parameterizations. Mon. Wea. Rev., 121,767-787.

Grell, G. A., J. Dudhia, and D. R. Stauffer, 1995: A Description of the fifth-generation Penn State/NCAR mesoscale modeling system (MM5). NCAR technical note, NCAR/TN398+STR, $121 \mathrm{pp}$.

Johnson, R. H., and P. E. Ciesielski, 2002: Characteristics of the 1998 summer monsoon onset over the Northern South China Sea. J. Meteor. Soc. Japan, 80, 561-578.

Kueh, M.-T., and S.-C. Lin, 2001: East Asian summer monsoon - Onset definition and circulation characteristics during onset period. Atmos. Sci., 29, 141-170. (in Chinese)

Lau, K.-M., and S. Yang, 1997: Climatology and interannual variability of the Southeast Asian summer monsoon. Adv. Atmos. Sci., 14, 141-161.

Li, C., and J. Wu, 2000: On the onset of the South China Sea summer monsoon in 1998. Adv. Atmos. Sci., 14, 176-194.

Lin, P.-H., 1996: The Asian summer monsoon and Mei-Yu front. Ph.D. dissertation, Department of Atmospheric Sciences, National Taiwan University, 180pp. (in Chinese)

Purdom, J. F. W., 1973: Mesohighs and satellite imagery. Mon. Wea. Rev., 101, 180-181.

Purdom, J. F. W., 1979: The development and evolution of deep convection. Proc. of the $11^{\text {th }}$ Conf. On Severe Local Storms, October 2-5, Kansas City, MO, Amer. Meteor. Soc., Boston, MA, 143-150.

Shao, H., and Y. Qian, 2000: Main features of regional circulation variation during onset of the South China Sea summer monsoon in 1998. Adv. Atmos. Sci., 17, 322-338.

Tao, S.-Y., and L.-X. Chen, 1987: A review of recent research on the East Asian monsoon in China. Monsoon Meteorology, C.-P. Chang and T. N. Krishnamurti Eds., Oxford Univ. Press, 60-92.

Zhang, D.-L., and R. A. Anthes, 1982: A high-resolution model of the planetary boundary layer-Sensitivity tests and comparisons with SESAME-79 data. J. Appl. Meteor., 21, 1594-1609.

Zhang, D.-L., and J. M. Fritsch, 1986: Numerical simulation of the meso- $\beta$-scale structure and evolution of the 1977 Johnstown flood. Part I: Model description and verification. J. Atmos. Sci., 43, 1913-1943.

Zhang, D.-L., and J. M. Fritsch, 1987: Numerical simulation of the meso- $\beta$-scale structure and evolution of the 1977 Johnstown flood. Part II: Inertially stable warm-core vortex and the mesoscale convective complex. J. Atmos. Sci., 44, 2593-2612.

Zhang, D.-L., and N. Bao, 1996a: Oceanic cyclogenesis as induced by a mesoscale convective system moving offshore. Part I: A 90-h real-data simulation. Mon. Wea. Rev., 124, 1449-1469.

Zhang, D.-L., and N. Bao, 1996b: Oceanic cyclogenesis as induced by a mesoscale convective system moving offshore. Part II: Genesis and thermodynamic transformation. Mon. Wea. Rev., 124, 2206-2225. 